\title{
Cluster observations of the high-latitude magnetopause and cusp: initial results from the CIS ion instruments
}

\author{
J. M. Bosqued ${ }^{1}$, T. D. Phan ${ }^{2}$, I. Dandouras ${ }^{1}$, C. P. Escoubet ${ }^{3}$, H. Rème ${ }^{1}$, A. Balogh ${ }^{4}$, M. W. Dunlop ${ }^{4}$, D. Alcaydé ${ }^{1}$, \\ E. Amata ${ }^{5}$, M.-B. Bavassano-Cattaneo ${ }^{5}$, R. Bruno ${ }^{5}$, C. $_{\text {Carlson }}^{2}$, A. M. DiLellis ${ }^{5}$, L. Eliasson ${ }^{6}$, V. Formisano ${ }^{5}$, \\ L. M. Kistler ${ }^{7}$, B. Klecker ${ }^{8}$, A. Korth ${ }^{9}$, H. Kucharek ${ }^{8}$, R. Lundin ${ }^{6}$, M. McCarthy ${ }^{10}$, J. P. McFadden ${ }^{2}$, E. Möbius ${ }^{7}$, \\ G. K. Parks ${ }^{2}$, and J.-A. Sauvaud ${ }^{1}$ \\ ${ }^{1}$ CESR, Toulouse, France \\ ${ }^{2}$ University of California, Berkeley, CA, USA \\ ${ }^{3}$ ESTEC/ESA, Noordwijk, the Netherlands \\ ${ }^{4}$ Blackett Laboratory, Imperial College, London, UK \\ ${ }^{5}$ IFSI, Rome, Italy \\ ${ }^{6}$ SISP, Kiruna, Sweden \\ ${ }^{7}$ University of New Hampshire, Durham, NH, USA \\ ${ }^{8} \mathrm{MPE}$, Garching, Germany \\ ${ }^{9}$ MPAe, Lindau, Germany \\ ${ }^{10}$ University of Washington, Seattle, WA, USA
}

Received: 17 April 2001 - Revised: 13 July 2001 - Accepted: 19 July 2001

\begin{abstract}
Launched on an elliptical high inclination orbit (apogee: $19.6 R_{E}$ ) since January 2001 the Cluster satellites have been conducting the first detailed three-dimensional studies of the high-latitude dayside magnetosphere, including the exterior cusp, neighboring boundary layers and magnetopause regions. Cluster satellites carry the CIS ion spectrometers that provide high-precision, 3D distributions of low-energy $(<35 \mathrm{keV} / \mathrm{e})$ ions every $4 \mathrm{~s}$. This paper presents the first two observations of the cusp and/or magnetopause behaviour made under different interplanetary magnetic field (IMF) conditions. Flow directions, 3D distribution functions, density profiles and ion composition profiles are analyzed to demonstrate the high variability of high-latitude regions. In the first crossing analyzed (26 January 2001, dusk side, IMF- $B_{Z}<0$ ), multiple, isolated boundary layer, magnetopause and magnetosheath encounters clearly occurred on a quasi-steady basis for $\sim 2$ hours. CIS ion instruments show systematic accelerated flows in the current layer and adjacent boundary layers on the Earthward side of the magnetopause. Multi-point analysis of the magnetopause, combining magnetic and plasma data from the four Cluster spacecraft, demonstrates that oscillatory outward-inward motions occur with a normal speed of the order of $\pm 40 \mathrm{~km} / \mathrm{s}$; the thickness of the high-latitude current layer is evaluated to be of the order of 900-1000 km. Alfvénic accelerated flows and D-shaped distributions are convincing signatures of a magnetic reconnection occurring equatorward of the Cluster satellites. Moreover, the internal magnetic and plasma structure of a flux transfer event (FTE) is analyzed in detail; its size along the magnetopause surface is $\sim 12000 \mathrm{~km}$ and it
\end{abstract}

Correspondence to: J. M. Bosqued (bosqued@ cesr.fr) convects with a velocity of $\sim 200 \mathrm{~km} / \mathrm{s}$. The second event analyzed ( 2 February 2001) corresponds to the first Cluster pass within the cusp when the IMF- $B_{Z}$ component was northward directed. The analysis of relevant CIS plasma data shows temporal cusp structures displaying a reverse energy-latitude "saw tooth" dispersion, typical for a bursty reconnection between the IMF and the lobe field lines. The observation of Dshaped distributions indicates that the Cluster satellites were located just a few $R_{E}$ from the reconnection site.

Key words. Magnetospheric physics (magnetopause, cusp, and boundary layers; magnetosheath) Space plasma physics (magnetic reconnection)

\section{Introduction}

Accelerated magnetosheath plasma flows within the boundary layers adjacent to the magnetopause have long been considered as one of the most convincing signatures of reconnection between the interplanetary (IMF) and magnetospheric magnetic fields, as originally predicted by Dungey (1961). Direct information on the particle penetration processes has been obtained on the dayside magnetopause, at low-latitudes (Paschmann et al., 1979; Sonnerup et al., 1981; Gosling et al., 1990; Scurry et al., 1994). At medium and higher latitudes, pioneering observations were carried out during the 1970s by Heos 2 in the plasma mantle (Rosenbauer et al., 1975), in the entry layers (Paschmann et al., 1976), and by Prognoz-7 in the same regions (Lundin, 1985; and references therein). Indirect measurements in the mid and low altitude cusps, such as the energy latitude dispersion (Reiff et al., 
1977, 1980; Escoubet et al., 1997a) and V-shaped energypitch angle dispersions (Menietti and Burch, 1988) have all been considered as arguments in favour of an ion injection at a reconnection site. From ion precipitation signatures observed by satellites crossing the low-altitude cusp and from the ground, indirect arguments have been presented in favour of patchy reconnection (Lockwood and Smith, 1992, 1994; Escoubet et al., 1992).

When the IMF is southward pointing, much knowledge about the processes acting at or near the magnetopause has been accumulated (Russell, 1995, and references therein). In spite of that, a number of related questions are still open: why isn't the predicted flow acceleration observed during each magnetopause crossing? How unsteady is the reconnection rate at the magnetopause? What are the microscale processes operating at the magnetopause? Does the diffusion dominate in the transport processes at high-latitudes? What are the detailed properties and the frequency of occurrence of propagating flux transfer events (FTEs) discovered by Russell and Elphic (1978)? Are the FTEs connected to upstream pressure pulses, or the signature of a sporadic reconnection?

On the other hand, evidence for reconnection when the IMF is northward is more recent. Dungey (1963) first suggested that a IMF pointing northward can lead to reconnection between the IMF and open field lines of the lobes, poleward of the cusp regions, driving a localized sunward flow. Indirect evidence of such a sunward convection flow was given (a) in the dayside polar cap by ground magnetograms (Maezawa, 1976) and auroral emissions (Oeireset et al., 1997), (b) at low- (Reiff, 1984; Escoubet and Bosqued, 1989) and mid- (Woch and Lundin, 1992) altitudes by satellite observations of reverse energy-latitude dispersions. In situ high-latitude observations for IMF- $B_{Z}>0$ are more scarce and recent (Gosling et al., 1991; Kessel et al., 1996; Chen et al., 1997; Fuselier et al., 2000).

Another evidence of reconnection (either when IMF- $B_{Z}>$ 0 or $<0$ ), not completely explored until now, can be found in the details of distribution functions measured at or near the magnetopause current layer and in the adjacent low- or highlatitude boundary layers. Only a limited part of an initial magnetosheath distribution in velocity space can be transmitted across the magnetopause (Cowley, 1982). Therefore, distributions must exhibit a characteristic D-shape, but just a few have been observed in the low-latitude boundary layers (Gosling et al., 1991; Fuselier et al., 1991; Phan et al., 2001) and very recently at high-latitudes by Polar (Fuselier et al., 2000).

To summarize, the search for detailed reconnection signatures near the magnetopause at high-latitudes remains one of the major goals of magnetospheric research and constitutes one of the most ambitious objectives of the multi-point Cluster mission.

The four identical satellites of the ESA Cluster Mission were launched in pairs on 15 July and 9 August 2000. One of the major goals of Cluster is to determine the local orientation and the state of motion of the small- and medium-scale plasma structures, such as the magnetopause, and thereby give, for the first time an unambiguous indication in order to distinguish between spatial and, temporal variations (Escoubet et al., 1997b). The current polar orbit has a perigee of $\sim 4 R_{E}$ and an apogee of $\sim 19.7 R_{E}$, an inclination of $90^{\circ}$, a line of apsides around the ecliptic plane, and an orbital period of $\sim 58$ hours. Orbital parameters of the four satellites differ slightly in order to achieve an almost perfect tetrahedral configuration in the external cusp and magnetopause.

For this initial study, we use ion data provided by the CIS instrument, supplemented by magnetic field measurements made by the FGM instruments, to survey two earlier Cluster passes near the magnetopause and in the exterior cusp, on 26 January and 2 February 2001 . On 26 January, the Cluster spacecraft remained near the magnetopause for more than 2 hours, with several repeated encounters with the current layer. On 2 February, Cluster crossed the high-latitude exterior cusp during a northward IMF. In both cases, our main goals are to show: (a) how these new multi-point observations are valuable for studying the dynamics of the highlatitude magnetopause and cusps and (b) what are the observed signatures of the magnetic reconnection. With the spacecraft separated by $\sim 600 \mathrm{~km}$ in the earlier phase of the mission, we are able to start defining the shape, structure, and motion of the magnetopause and cusp region, the detailed properties of FTEs, and the size and motion of the different layers crossed near the magnetopause.

Our paper is organized as follows. In Sect. 2, we give the useful information on the performance of the Cluster Ion Spectrometry (CIS) instruments. A preliminary analysis of the results obtained during a high-latitude, duskward pass (26 January 2001) is given in Sect. 3. The interplanetary magnetic field (IMF) had a southward component, and clear reconnection signatures (accelerated flows) can be seen at the magnetopause; we perform a rigorous multi-spacecraft analysis of one of the magnetopause inward-outward motions, as well as a detailed analysis of an FTE pulse observed during the same pass. In Sect. 4 , the example presented (2 February 2001) is the first Cluster high-latitude pass for a northward IMF. A structured cusp is evident and presumably it results from reconnection between the IMF and lobe field lines, poleward of the satellites.

\section{Instrumentation}

The Cluster Ion Spectrometer (CIS) experiment described in greater detail in Rème et al. (2001, this issue) provides full $3 \mathrm{D}$ simultaneous ion distribution functions up to $\sim 40 \mathrm{keV} / \mathrm{e}$ for the major ion species, with a time resolution of up to $4 \mathrm{~s}$ (i.e. 1 spin period). Two different instruments are used to cover the needed energy, angle, dynamic flux ranges, and mass requirements. A special feature of CIS is the double sensitivity of the instruments that allow precise measurements under extreme flux conditions. 
First, the Hot Ion Analyzer (HIA) sensor (CIS2 instrument) selects ions according to their energy per charge, using a top hat, quadrispherical electrostatic analyzer with a uniform $360^{\circ} \times 5^{\circ}$ disc-shaped field-of-view. The instrument has two $180^{\circ}$ sections with different sensitivities and it lies parallel to the spin axis, called "high $G$ " and "low $g$ ". The low $g$ section, with a sensitivity attenuated by a factor of $\sim 24$, analyses the high intensity solar wind with an angular resolution of $5.6^{\circ}$. To allow for precise measurements, the sweep energy range can be automatically adjusted on each spin. The high $G$ sensitive section detects magnetospheric ions over the full energy range from $\sim 5 \mathrm{eV} / \mathrm{e}$ to $\sim 32 \mathrm{keV} / \mathrm{e}$. A full $(16 \theta \times 32 \varphi)$ angle's pixels multiplied by 31 energy steps yields a 3D distribution for every spin. Distribution functions used in this paper are detected in the high $G$ section and are constructed by using $(8 \theta \times 16 \varphi)$ angle pixels (in reality, reduced to 88 ) and 31 energy steps; distributions were on board and accumulated over 3 spins $(\sim 12 \mathrm{~s})$.

The CIS-1 instrument is the time-of-flight ion Composition and Distribution Function Analyzer (CODIF), which is a high-sensitivity mass-resolving spectrometer capable of providing full 3D distributions of the major ion species $\left(\mathrm{H}^{+}, \mathrm{He}^{2+}, \mathrm{He}^{+}, \mathrm{O}^{+}\right)$in the energy range $\sim 20 \mathrm{eV} / \mathrm{e}$ to $\sim 40 \mathrm{keV} / \mathrm{e}$; this range is extended by an additional Retarding Potential Analyzer (RPA) that covers the energies between the spacecraft potential and about $25 \mathrm{eV} / \mathrm{e}$. In order to cover the large anticipated flux dynamic range, the CIS-1/CODIF instrument has also been divided into two $180 \times 8^{\circ}$ fanshaped sections, the "High Side" (HS) and the "Low Side" (LS) sections, that differ in sensitivity by a factor of $\sim 100$; in the solar wind, in general, the LS section is used. 3D full phase space distributions for each ion species are transmitted to the telemetry. Data used in this paper are 3D (88-angle pixels multiplied by 31 or 16 energy steps) distributions from the HS and/or the LS sections, accumulated over 3 or 4 spins.

Extensive onboard data processing allows for continuous and systematic transmission every spin $(\sim 4 s)$ of the basic moments of the 3D distribution functions, measured by the two CIS instruments, according to the section selected. Transmitted moments are the ion density, $N_{i}$, of the major ion species, the flow vector, $\boldsymbol{V}_{i}$, the heat flux vector, $\boldsymbol{H}_{i}$, and the pressure tensor, $\mathbf{P}$.

Due to an unidentified electronic failure, both CIS instruments on Cluster spacecraft 2 were switch off following the commissioning tests. Moreover, the CIS-2/HIA instrument was also switched off on spacecraft 4 for the period presently studied. To summarize, data presented in this paper come from the CIS-1 instruments on three spacecraft (1, 3, and 4) and from the CIS-2 instruments on two spacecraft (1 and 3).

The magnetic field measurements were obtained from the FGM instrumentation (Balogh et al., 1997). It consists of two tri-axial fluxgate magnetometers and an associated dataprocessing unit that provides accurate, high time resolution measurements of the magnetic field vector. Data used in this paper do not have the full FGM resolution but are averaged over the spin period $(\sim 4 \mathrm{~s})$. Higher time resolution data $(\sim 1 \mathrm{~s})$ are used to determine time delays.

\section{First case study: 26 January 2001, southward IMF}

This example from 26 January 2001 was chosen as one of the first to show a two-hour extended period $(\sim 09: 00$ 11:00 UT) of multiple encounters with the high-latitude boundary layer/magnetopause interface in the northern dusk sector $(\sim$ 15:00 LT). These multiple crossings are unambiguously accompanied by accelerated flows within the current layer and boundary layer, with a higher flow speed than in the adjacent magnetosheath. Such signatures can indicate a steady reconnection site not far from the Cluster location.

Figure 1 shows the interplanetary magnetic field (IMF) and solar plasma measurements provided by the ACE satellite located close to the L1 Lagrangian point, more than $220 R_{E}$ upstream of the magnetosphere. From a comparison with similar Geotail data (Geotail is located on the dawnside magnetosheath) and Wind data, the probable time delay between ACE and the front magnetosphere can be evaluated to be around $65 \mathrm{~min}$. During the interval of interest for Cluster (i.e. from $\sim$ 07:00 UT to $\sim 15: 00 \mathrm{UT}$ ), the solar wind dynamic pressure does not change drastically and stays at $\sim 0.8 \mathrm{nPa}$. The IMF is oriented duskward/southward before 09:00 UT $\left(B_{X} \sim 1.5 \mathrm{nT}, B_{Y} \sim 2 \mathrm{nT}, B_{Z} \sim-6 \mathrm{nT}\right.$ at 08:00 UT) and suddenly turns steadily dawnward/southward $\left(B_{Y} \sim-6 \mathrm{nT}\right)$ with a small, positive $B_{X}$ component. Between 10:00 UT and 11:00 UT, the IMF is very steady $(+0.5,-6,-3 \mathrm{nT})$ and, according to this direction, a possible site of reconnection is located on the duskward side of the magnetopause (Crooker, 1979).

\subsection{Overview of CIS and FGM data}

Magnetic field and ion plasma data provided by the FGM and CIS instruments on board the Cluster spacecraft 3 are combined and displayed in Fig. 2 for the interval 06:0012:00 UT on 26 January 2001, for an outbound pass near the cusp and magnetopause. Different regions can be easily identified along the Cluster orbit, starting from the almost empty northern magnetospheric lobe (connected to the polar cap), and passing at $\sim 06: 50$ UT into the low-energy $(\sim 100 \mathrm{eV} / \mathrm{e})$ plasma mantle characterized by a density that slowly increases from 0.1 to $0.7 \mathrm{~cm}^{-3}$ at $\sim 08: 05 \mathrm{UT}$, and a tailward/duskward-directed low-speed flow $(\leq 30 \mathrm{~km} / \mathrm{s})$. The magnetic field has an orientation $\left(\theta \sim-45^{\circ}, \varphi \sim-80^{\circ}\right)$ typical of the high-latitude open lobe field lines on the northern dusk side. At $\sim$ 08:04 UT, a new, hotter plasma regime appears, with successive (5-6) bursty structures at considerably higher densities (reaching $\sim 2 \mathrm{~cm}^{-3}$ ) and a continuously increasing average ion energy with the temperature reaching $\sim 2 \mathrm{keV}$ at the boundary detected at $\sim 08: 45 \mathrm{UT}$. The field line inclination is slowly rotating. From the plasma properties, we consider this part to be the exterior cusp and/or the entry layer. The next region reached from $\sim 08: 45$ to $\sim 09: 15$ UT is certainly the dayside extent of the plasma sheet on closed field lines. When moving outward, the magnetic field rotates from $\theta \sim-35^{\circ}$ to $\varphi \sim 0^{\circ}$ at $\sim 09: 00$ UT $\left(3.27,6.56,9.01 R_{E} \mathrm{GSE}\right)$ and finally, to $+40^{\circ}$, which is typ- 


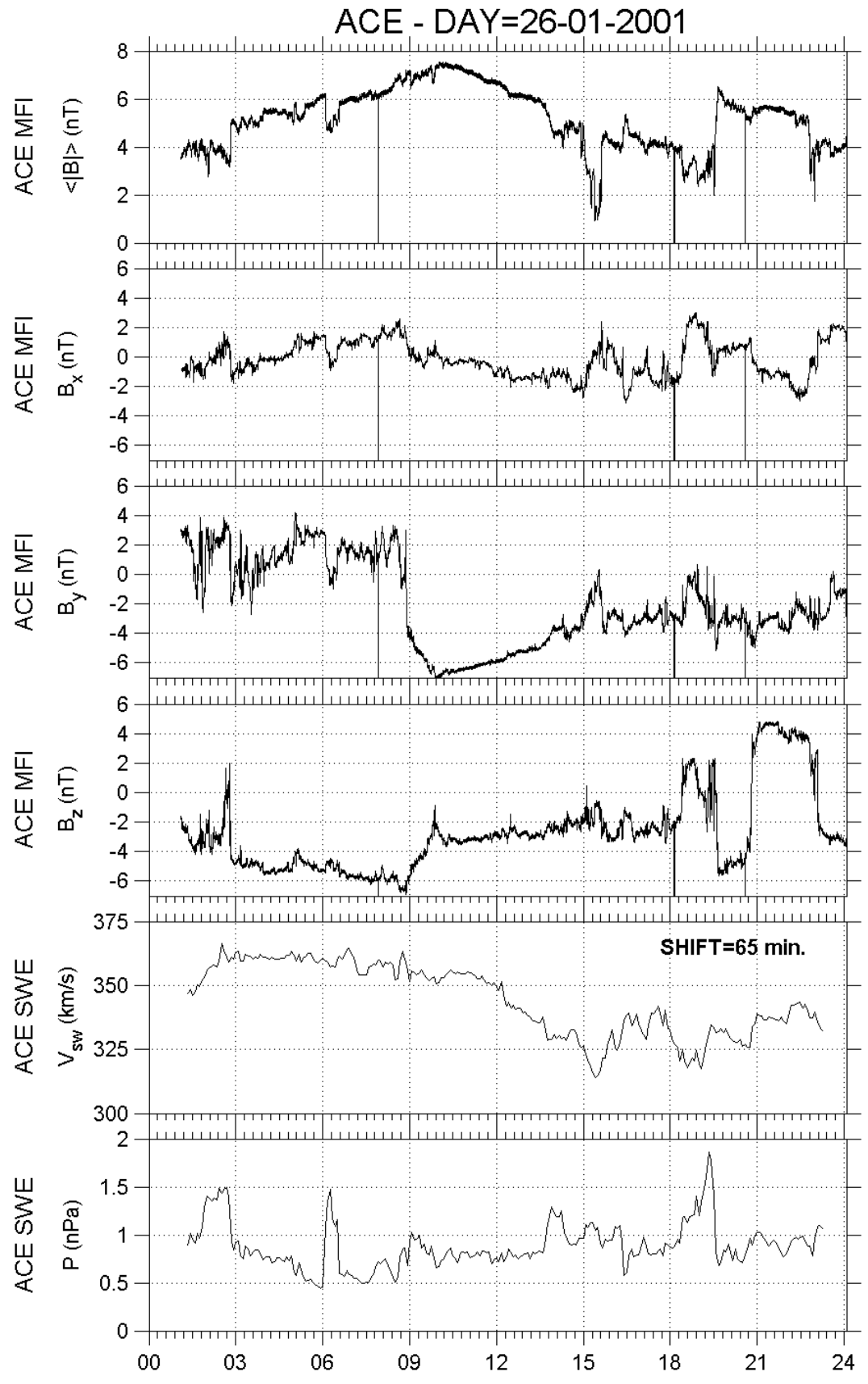

Fig. 1. Upstream ACE interplanetary data from 26 January 2001. From top to bottom the panels display the total magnetic field amplitude (in nT), the three components $\left(B_{X}, B_{Y}, B_{Z}\right)$ of the interplanetary magnetic field (IMF) in GSE coordinates, the solar wind velocity (in $\mathrm{km} / \mathrm{s}$ ) and dynamic pressure (in $\mathrm{nPa}$ ).

ical for closed field lines on the dusk side. A significant population of high energy $(\geq 5 \mathrm{keV})$ hot ions is evident on the spectrogram, presumably of magnetospheric (plasma sheet) origin. However, a number of narrow, high-speed flows (directed along $-V_{Y}$ ) are apparent within this region.

Analysis of the next interval to about 11:04 UT constitutes the main topic of the following presentation. Cluster satellites sequentially encounter the magnetopause and boundary layer populations before exiting into the magnetosheath regime $\left(N_{i} \sim 25 \mathrm{~cm}^{-3}, T_{i} \sim 10^{2} \mathrm{eV}\right)$. The populations are identified there, as expected, for the post-noon sector at northern altitudes by a tailward/duskward/northward plasma flow with $V_{X} \sim-150 \mathrm{~km} / \mathrm{s}, \quad V_{Y} \sim V_{Z} \sim+50 \mathrm{~km} / \mathrm{s}$. The magnetosheath field is draped around the magnetopause orientation $\left(\theta \sim-20^{\circ}, \varphi \sim-60^{\circ}\right)$, but directed sunward/duskward/southward as the IMF is measured by ACE or WIND. It should be noted that the first bow shock crossing occurs at $\sim 15: 30 \mathrm{UT}$ (outside the figure). For convenience, this region is divided into two parts, 09:0010:00 UT and 10:00-11:00 UT.

Concentrating first on the ion spectrogram (bottom panel) and the flow speed panel of this transition region, intermittent, clearly accelerated plasma flows are observed in the 09:00-10:00 UT interval, according to a periodic se- 


\section{CLUSTER - SC3 - DAY =26-01-2001}

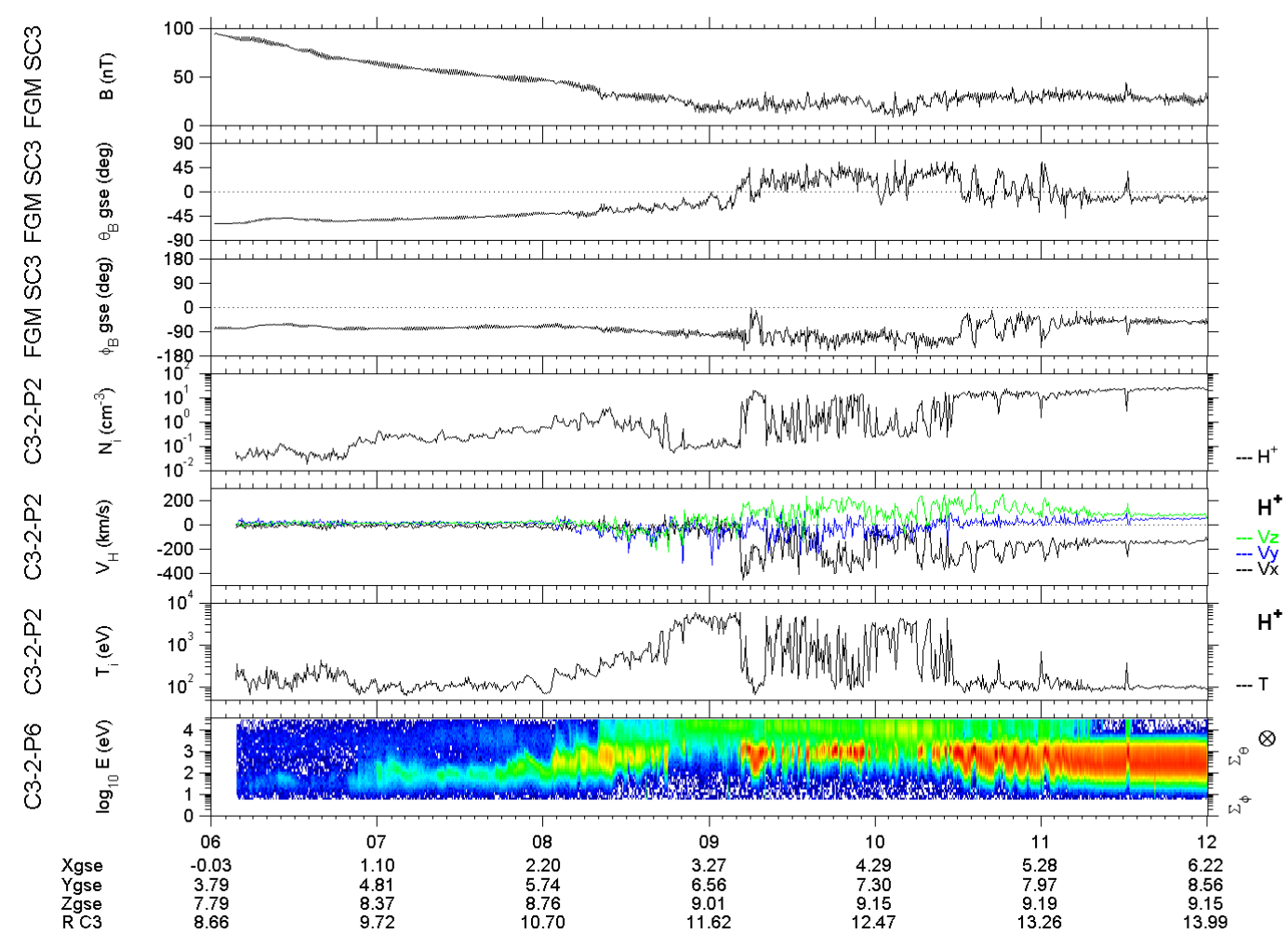

Fig. 2. Magnetic field and ion plasma data from Cluster/spacecarft 3, FGM and CIS instruments, for 06:00-12:00 UT during the high-latitude crossing on 26 January 2001. From top to bottom successive panels display: the $4 \mathrm{~s}$ averaged FGM magnetic field strength (in nT), magnetic field elevation $\theta$ and azimuth $\varphi$ (in GSE coordinates), the $4 \mathrm{~s}$ resolution on board-computed moments, i.e. full ion density ( $\mathrm{cm}^{-3}$ ), the three components of the flow speed $(\mathrm{km} / \mathrm{s})$, and the ion temperature $(\mathrm{eV})$, and the $12 \mathrm{~s}$ resolution colour-coded E-time spectrogram from $\sim 5 \mathrm{eV}$ to $\sim 34 \mathrm{keV} / \mathrm{e}$, integrated over all azimuths and elevations (1D). Counts per second are colour-coded according to the logarithmic colour bar shown on the right to emphasize the energy flux and presence of high energy ions and not the density. All ion data are provided by the "C3-2" instrument (spacecraft Cluster 3 - CIS 2 instrument, without mass analysis).

quence. Each accelerated plasma jet, with speed higher than $350 \mathrm{~km} / \mathrm{s}$, has a density ranging from 8 to $20 \mathrm{~cm}^{-3}$, slightly lower than the magnetosheath plasma density (after 11:10 UT) but considerably higher than in the adjacent plasma sheet density (before 09:10UT). It is worth noting that all of these accelerated flows are superposed onto a nonnegligible background of hot $\left(T_{i} \geq 3 \mathrm{keV}\right)$ magnetospheric ions with a density of $\sim 0.1 \mathrm{~cm}^{-3}$. The highest bulk flows are directed Earthward along $-X$ with an important $+Z$ component, which means that the flows are directed roughly parallel to the magnetopause surface. The ion temperature, $1-3 \cdot 10^{2} \mathrm{eV}$, is slightly warmer than in the magnetosheath.

A close examination of the magnetic field angles (top panels) shows: (a) all of the accelerated flow events in this time interval are correlated with small rotations of the magnetic field direction from its magnetosphere-like configuration to an intermediate direction, where periodic rotations of about $15^{\circ}$ in $\theta$ and $\sim 40^{\circ}$ in the angles are clearly seen, (b) except for the notable short incursion around 09:15 UT, these field changes are insufficient to indicate successive magnetopause crossings, such as those observed in the next time interval

\section{(10:20-11:20 UT).}

From the plasma and field observations, we may conclude that for most of this time interval, the Cluster satellites, positioned almost tangentially along the magnetopause surface, remain inside the magnetopause plasma layer, i.e. according to the definitions introduced by Song (1995) for the highlatitude plasma layer (HBL) and the current or "sheath transition" layer. Due to oscillations of the surface, with a period of about $3 \mathrm{~min}$, the Cluster satellites skim a series of accelerated flow events without completely crossing the current layer. However, a detailed examination of high-speed flows around the first current sheet magnetopause crossing at 09:15 UT, followed by the immediate return to the inner boundary layer at $\sim 09: 18 \mathrm{UT}$, indicates that the highest speed flow is well located near the Earthward edge of the current layer where the density is the highest. Moreover, the magnetospheric-like plasma extends outward from the current layer, and disappears only around 09:17 UT when the spacecraft are located deeper in the magnetosheath.

Data for the 10:20-11:20 UT interval are shown in Fig. 3, where high-speed flows are highlighted by vertical lines. 
Similar to the events detected between 09:00 and 10:00 UT, the first series of short-lived accelerated flows between 10:20 and 10:30 UT is not associated with a complete crossing of the current layer and the magnetopause. Between the accelerated flows, Cluster remains on plasma sheet field lines, characterized by a hot magnetospheric ( $>5 \mathrm{keV}$ energy) plasma. The following most significant events at $\sim$ 10:30 UT, $\sim 10: 36 \mathrm{UT}, \sim 10: 46 \mathrm{UT}, \sim 10: 51 \mathrm{UT}, 10: 55 \mathrm{UT}, 11: 02 \mathrm{UT}$ are periodic, transient, accelerated plasma flows observed during the complete transition from the high-latitude boundary layer (HBL) to the magnetosheath through the current layer and magnetopause. Large $\boldsymbol{B}$ rotations, from its magnetosphere orientation $\left(\theta \sim+40^{\circ}, \varphi \sim-135^{\circ}\right)$ to its adjacent magnetosheath orientation $\left(\theta \sim-20^{\circ}, \varphi \sim-45^{\circ}\right)$, are unambiguous signatures of magnetopause traversals, and are systematically associated with the presence of the accelerated flows, as is evident in the general figure for this event. The flow jump is of the order of $150 \mathrm{~km} / \mathrm{s}$ and is nearly in the tailward northward direction (e.g. $V_{X} \sim-400, v_{Z} \sim+200 \mathrm{~km} / \mathrm{s}$ at 10:35 UT), and is concentrated within a thin layer on the Earthward side of the magnetopause itself. Density and temperature properties remain identical to those already mentioned for the previous events. It is important to note that successive transitions towards the magnetosheath-like plasma are evidenced by a flow speed dispersion, from the accelerated flow down to the magnetosheath regime. Moreover, magnetospheric ions are still present within the magnetosheath on the sunward side of the magnetopause, with their density reaching its lowest level after 11:18 UT. Significant fluxes of high energy ( $>5 \mathrm{keV}$ ) ions were observed in the past at low- and medium-latitudes in the magnetosheath, just outside the magnetopause (see, for instance, Kudela et al., 1992). It seems likely that these ions escape via finite Larmor radius effects; this ion leakage will be the topic of future CIS studies.

\subsection{Multi-point measurements}

The initial results from the Cluster multi-satellite mission demonstrate, unequivocally, that this mission will be of great benefit for the separation space and time variations, particularly in the attempt to interpret successive encounters with propagating boundaries that separate different plasma regimes, such as the periodic inward-outward motion of the entire boundary layer/current layer/magnetopause/magnetosheath observed during this 26 January 2001 event.

Next, we discuss the use of the simultaneous observations made by the CIS instruments from three Cluster satellites to determine the inter-spacecraft propagation properties (velocity, direction) and then to obtain the thickness of the different layers, surface propagation of disturbances along the boundary, surface waves, possible distortions, etc. Before describing this first attempt to use measurements from CIS on the Cluster satellites, it is important to recall that the interspacecraft separation was only $600 \mathrm{~km}$ during the first part of the Cluster mission (until summer 2001), and that the best time resolution for $f(v)$ distributions is only $12 \mathrm{~s}$ ( 3 spins) for the events covered here. Therefore, the best available CIS parameters for inter-spacecraft comparisons are the full moments $\left(N_{i}, \boldsymbol{V}_{i}\right)$ computed on board every spin $(\sim 4 \mathrm{~s})$. Of course, magnetic field measurements allow for a much better resolution, even if we only use in this paper $1 \mathrm{~s}$ averaged resolution data.

The Cluster tetrahedron geometry at $\sim 10: 35$ UT is shown in Fig. 4 and can be considered conserved for the entire period of interest; at a quick glance, it appears that spacecraft 1 and 3 should belong to the magnetopause surface, and spacecraft 2 and 4 should, respectively, lead and end the tetrahedron along the orbit. In particular, spacecraft 4 may remain at $\sim 0.65 R_{E}(420 \mathrm{~km})$ along the normal to the surface.

Two examples of simultaneous 3-spacecraft Cluster/CIS measurements are presented, with the first one taken during two incomplete traversals of the magnetopause (between 10:24 and 10:28 UT), and the second for a complete inward-outward double crossing of the magnetopause (between 10:33 and 10:38 UT).

\subsubsection{Data interval: 10:24-10:28 UT}

Figure 5 shows simultaneous magnetic field orientations, partial density $(>5 \mathrm{keV})$, and density and bulk flow profiles for satellites 1, 3 and 4, for two accelerated flows separated by $\sim 2 \mathrm{~min}$ and lasting $\sim 1 \mathrm{~min}$; the three ion spectrograms are given in the bottom panels. First, it is evident that spacecraft 1 and 3 measure very similar enhanced plasma densities and total bulk velocity profiles; however, a small (4s) time delay was evident in the bulk velocity profile (spacecraft 3 leaving first) when the pair of satellites left the accelerated plasma layer at $\sim 10: 25: 55$ UT to returned to the less dense boundary layer, characterized by plasma mixing with a majority of high energy trapped magnetospheric ions. The same timing could be seen in the density and velocity details near 10:27:30 UT. Second, the two major accelerated increases in bulk flow and density are also identified by spacecraft 4 , but are attenuated and nested within the spacecraft 1 and 3 profiles. The time delay between spacecraft 4 and 3 at the re-entry point into the magnetospheric-like boundary layer (see vertical marks at $\sim$ 10:25:55 UT, at the spacecraft 4 first re-entry) and exit (at $\sim 10: 26: 35$ UT, spacecraft 4 last exit) is $\sim 8 \mathrm{~s}$. By neglecting the Cluster spacecraft motion $(<2 \mathrm{~km} / \mathrm{s})$, we can interpret this latest delay as the result from a back and forth motion of the magnetopause surface, with a velocity $\boldsymbol{u}_{n}$ of $\sim 40 \mathrm{~km} / \mathrm{s}$ along its normal (roughly aligned with the spacecraft 3 -spacecraft 4 line). The time delay deduced from the spacecraft 1 and 3 time differences $(\leq 4 \mathrm{~s}$ from CIS, $\leq 2 \mathrm{~s}$ from FGM) can be considered as a superposed $90 \mathrm{~s}$ period wavy oscillation propagating poleward along the magnetopause surface at a velocity of $\geq 120 \mathrm{~km} / \mathrm{s}$. Apparently this velocity is of the order of magnitude of the surface waves observed by the wave experiment on board Cluster (Cornilleau et al., 2001). In summary, given these measurements, the thickness of the plasma layer of accelerated flow can be crudely determined to be at $\sim 10: 00$ 


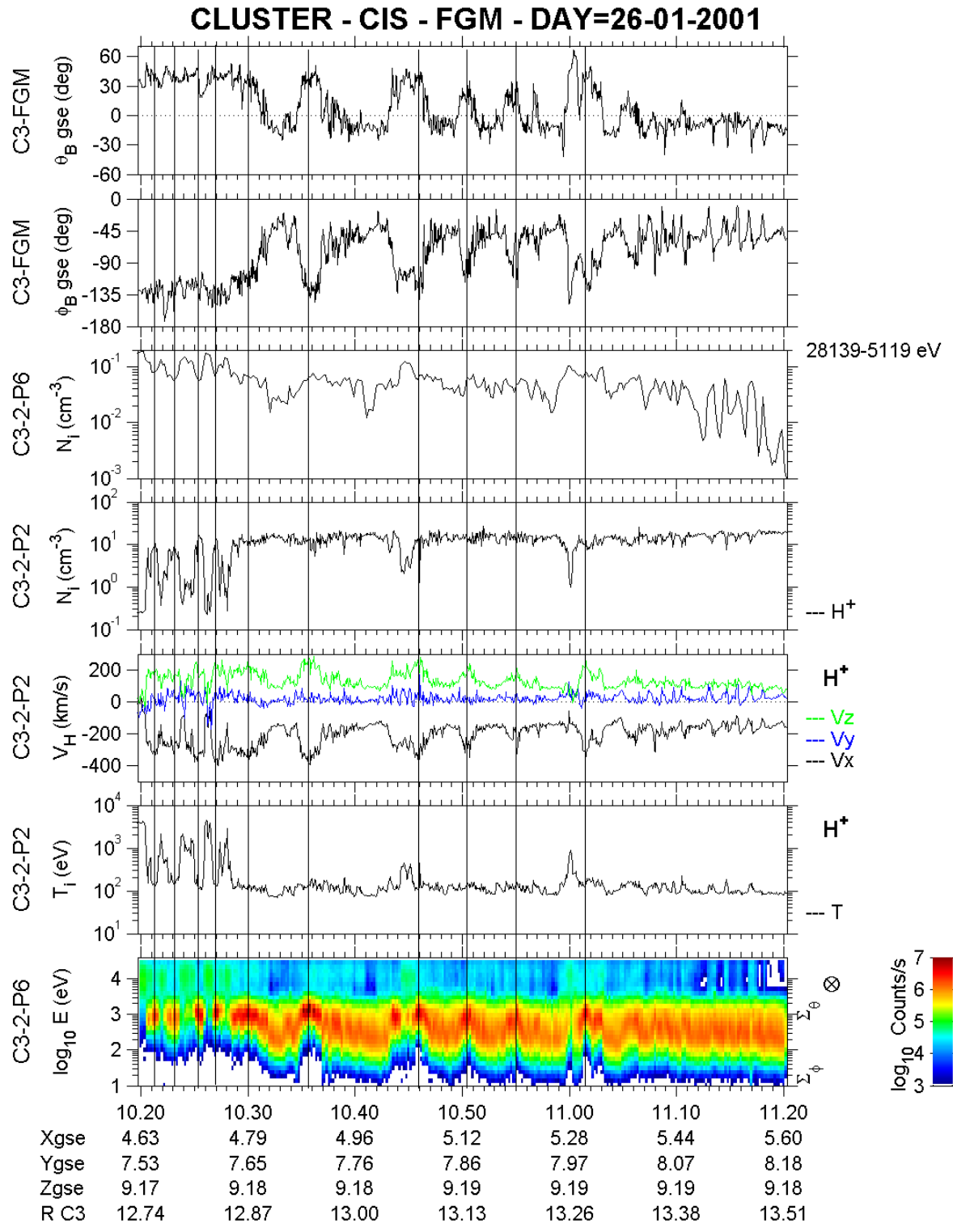

Fig. 3. Magnetic field and plasma data for the 10:20-11:20 UT interval provided by the FGM and CIS-2 instruments. From top to bottom, the magnetic field orientation $\theta$ and azimuth $\varphi$ angles (averaged over $4 \mathrm{~s}$ ), the partial $(5 \mathrm{keV})$ and total ion densities $N_{i}$ $\left(\mathrm{cm}^{-3}\right)$, the three components of the bulk flow speed, the scalar ion temperature, and the ion spectrogram are plotted. Total ion density, flow speed components, and temperature are computed on board with a $4 \mathrm{~s}$ time resolution (see Rème et al., 2001), while the partial density is computed on the ground from transmitted 3D distributions accumulated over 3 spins (i.e. $12 \mathrm{~s}$ resolution). Vertical lines correspond to flows with $\left|V_{X}\right|>350 \mathrm{~km} / \mathrm{s}$.

20:00 km. A more rigorous estimation of the magnetopause motion and size will be performed below on the next time segment, 10:33-10:38 UT.

\subsubsection{Data interval 10:33-10:38 UT}

The second inter-spacecraft comparison concerns the interval 10:33-10:38 UT during which the satellites make periodic crossings of the magnetopause, moving back and forth between the magnetosheath and the high-latitude boundary layer (Fig. 6). At 10:33 UT, the spacecraft are located within the magnetosheath-like plasma, as indicated by the relatively low density of energetic $(>5 \mathrm{keV})$ ions and the orientation of the magnetic field. Afterwards, the magnetic field orientation $\varphi_{B_{l m n}}$ in the $(L M)$ plane tangent to the magnetopause starts to rotate, while the normal component $\theta_{B_{l m n}}$ remains approximately constant. The four satellites enter the current layer around $\sim$ 10:34:12 UT for spacecraft 4 (FGM, red curve), and slightly later, at $\sim 10: 34: 25$ and at $\sim 10: 34: 32 \mathrm{UT}$, for spacecraft 3 and 2 (green and blue and lines) and spacecraft 1 (black line), respectively. The time lag between the spacecraft 1 and 3 measurements is even less evident at the shallow reentry in the magnetosheath around 10:36:50 UT; for its part, spacecraft 4 remains on the magnetospheric side of the current layer for the rest of the interval. Concerning the accelerated flows, the time delay is the same as that deduced from the magnetic field. Due to the relative outward motion of the magnetopause, the spacecraft 1 and 3 satellites detect a progressively accelerated flow just inside the current layer (or "sheath transition layer") between 10:34:26 and 10:35:10 UT (vertical black lines, region MP1) which reaches $>400 \mathrm{~km} / \mathrm{s}$ within the boundary layer, between $\sim 10: 35: 10$ and 10:36:40 UT. A gradient in the total density is not seen just at the boundary, but the density 


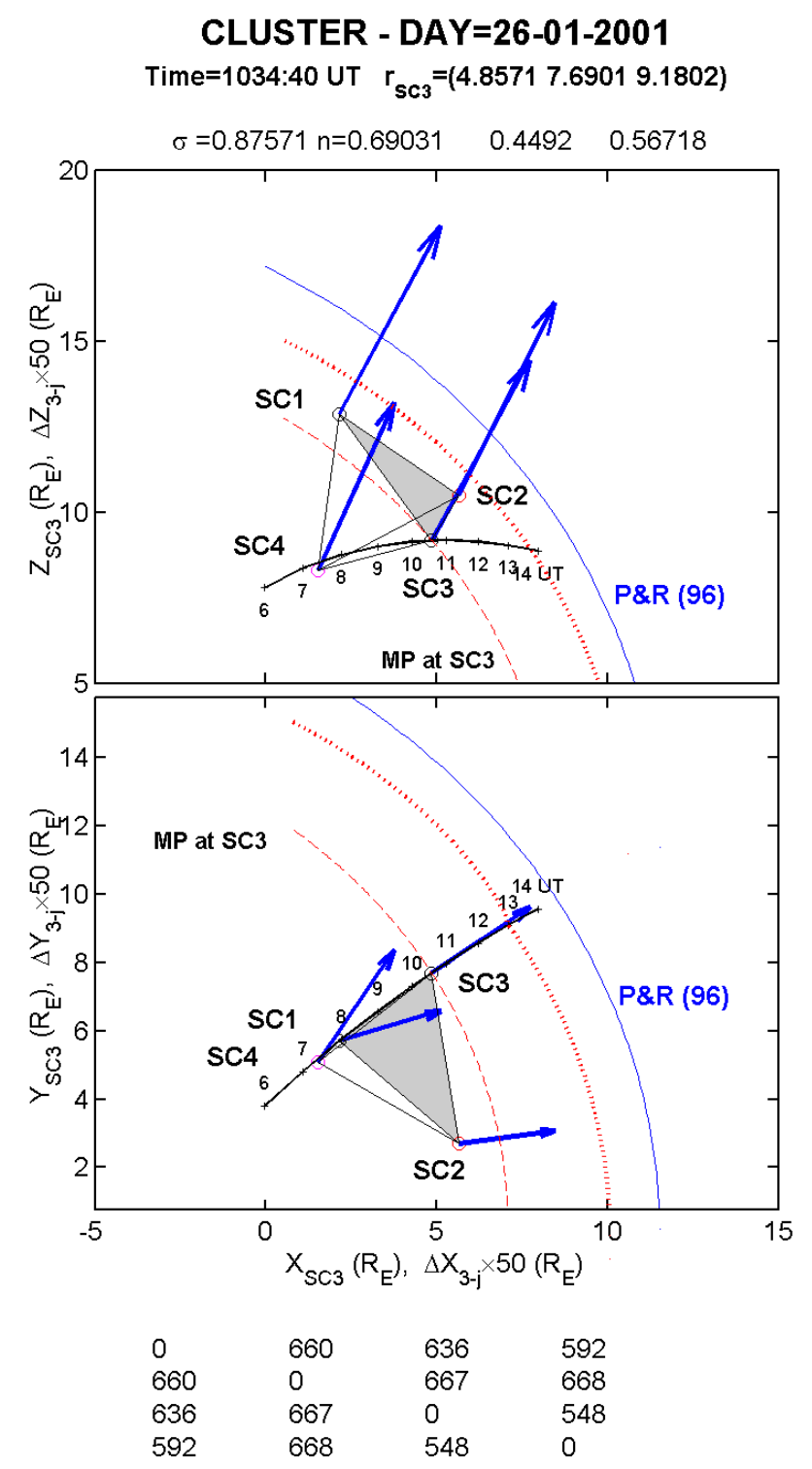

Fig. 4. Cluster spacecraft 3 orbit on 26 January 2001, from 06:00 to $14: 00 \mathrm{UT}$, projected onto the $X-Y$ (bottom) and $X-Z$ (top) GSE planes. The relative configuration of the Cluster tetrahedron at 10:35:00 UT, centered on spacecraft 3 is also mapped. For clarity, the inter-spacecraft distances have been multiplied by a factor of 50 . The solid and dotted lines give cuts in the $Y=0$ (top) and $Z=0$ (bottom) planes of: (a) the model magnetopause location (Petrinec and Russell, 1996) for IMF- $B_{Z}=-3 \mathrm{nT}$ and $P_{s w}=0.8 \mathrm{nT}$ (solid line); (b) the scaled magnetopause at spacecraft 3 (dotted line); the scaling factor is 0.875 . Magnetopause cuts at $Y=Y_{\mathrm{sc} 3}$ and $Z=Z_{\mathrm{sc} 3}$ are also given (dashed lines). On the same diagrams are also plotted for spacecraft 1,3 , and 4 , the components of the magnetopause normal vectors $\boldsymbol{n}_{E}$ predicted by the Maximum variance analysis of $\boldsymbol{E}=-\boldsymbol{V} \times \boldsymbol{B}$ (see text for details); the $\boldsymbol{n}_{B}$ normal vector is plotted for spacecraft 2 , the CIS instruments are switched off on spacecraft 2.

of higher energy ions increases when the spacecraft move Earthward relative to the boundary. Velocity gradients (and gradients in the magnetic field rotation) are sharper when the spacecraft reenter between $\sim 10: 36: 30$ and 10:37 UT (vertical blue lines, region MP2) in the magnetosheath regime, and do not show a measurable time lag in the CIS moments. At that time, spacecraft 4 was deeper in the Earthward side of the current layer.

\subsection{Evidence for reconnection at the magnetopause}

All the periodic enhanced flows observed during the full 09:00-11:06 UT period deserve special attention because they could provide signatures of merging. To investigate whether the field line merging process accounts for the accelerated flow, we have analyzed all magnetopause crossings by using the methods described in detail in Sonnerup et al. (1987, 1990) and Khrabrov and Sonnerup (1998); here, we present the results, summarized in Table 1, obtained for the time interval 10:33-10:38 UT, as shown in Fig. 6.

\subsubsection{Determination of normal vectors}

As a first step, we have performed a variance analysis either on the magnetic field data or on the convection electric field $\boldsymbol{E}_{c}=-\boldsymbol{V} \times \boldsymbol{B}$ (where $\boldsymbol{V}$ and $\boldsymbol{B}$ represent the flow velocity vector and the local magnetic field provided by CIS and FGM, respectively), either for two separated or optimized time intervals, marked M1 (shifted for spacecraft 4) and M2 in the Fig. 6, for the full-time data segment, 10:34:3010:37:00 UT. The direction of minimum of the variance of $\boldsymbol{B}$ and $\boldsymbol{n}_{B}$, and the direction of maximum of the variance of $\boldsymbol{E}_{c}$ and $\boldsymbol{n}_{E}$, are nearly identical; both are useful predictors of the magnetopause normal vector, and their differences are small, between 3.5 and $8^{\circ}$ (see Table 1). Normal directions are only given for the full data interval, as they are roughly similar for the individual magnetopause crossings.

$\boldsymbol{n}_{E}$ (or $\boldsymbol{n}_{B}$ for spacecraft 2) normal directions, projected onto the $X-Y$ and the $X-Z$ GSE planes, are plotted in Fig. 4. Comparing directions obtained for each spacecraft it may be noted differences of 9-14 degrees. Such differences are not really surprising and cannot be eliminated by changing the segment of data; they could reflect the presence of ripples on the magnetopause surface.

\subsubsection{Existence of a deHoffmann-Teller (DHT) frame}

The second step consists of searching for the existence of a dHT frame for each spacecraft, moving with a velocity $\boldsymbol{V}_{\mathrm{HT}}$ along the presumed RD discontinuity, in which the electric field vanishes (or nearly vanishes). Although not sufficient, this existence is one means of determining reconnection at the magnetopause. A constant $\boldsymbol{V}_{\mathrm{HT}}$ is determined by minimizing the quantity:

$D=\sum\left|\left(\boldsymbol{V}^{m}-\boldsymbol{V}_{\mathrm{HT}}\right) \times \boldsymbol{B}^{m}\right|^{2}$

summed over the set of individual data $\left(\boldsymbol{V}^{m}, \boldsymbol{B}^{m}\right)$; then the determination of $\boldsymbol{V}_{\mathrm{HT}}$ can be improved by including a constant acceleration $\boldsymbol{a}_{\mathrm{HT}}\left(\boldsymbol{V}_{\mathrm{HT}}=\boldsymbol{V}_{\mathrm{HT} 0}+\boldsymbol{a}_{\mathrm{HT}} t\right)$. The "quality" 


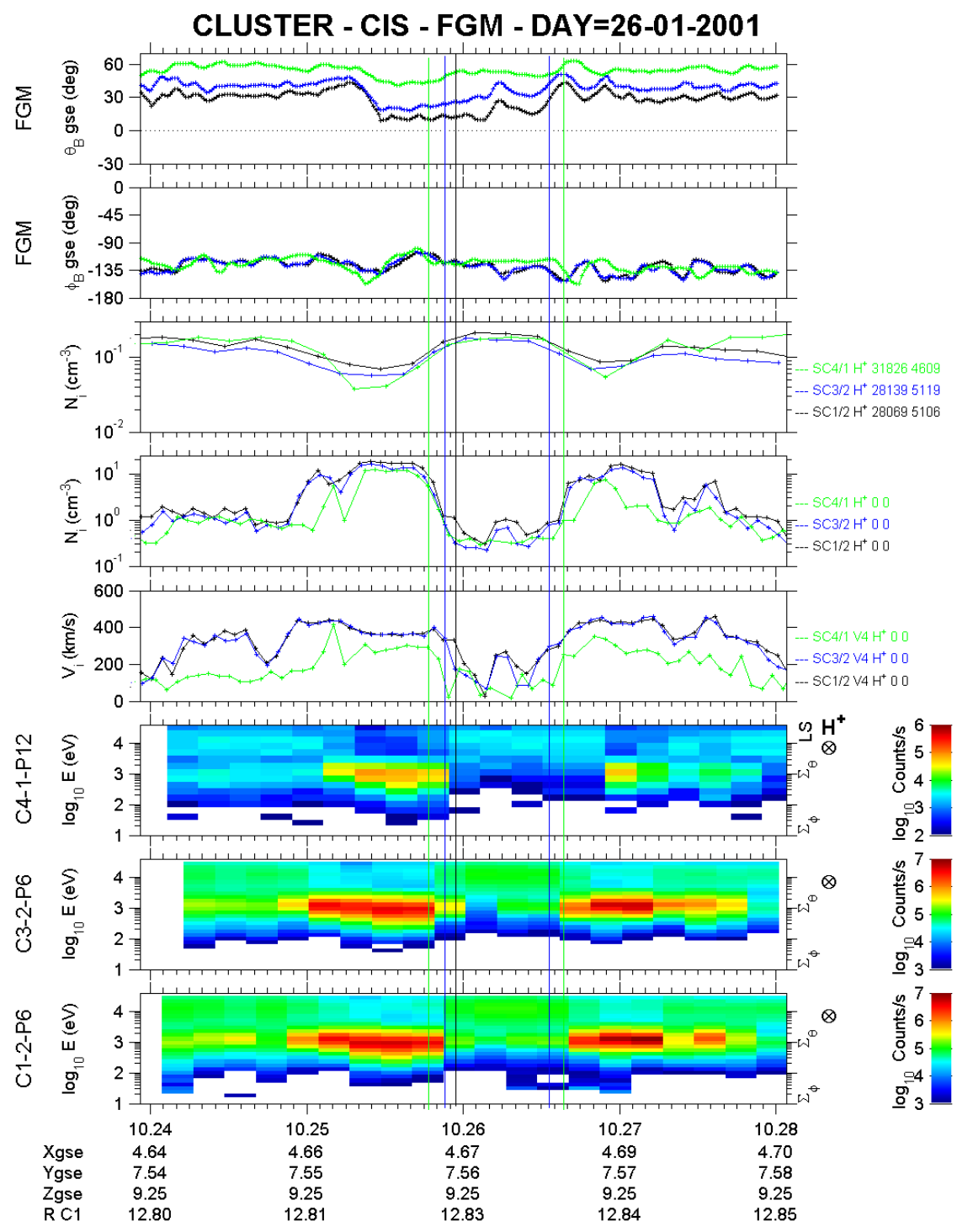

Fig. 5. Magnetic field angles and plasma data (partial density, total density, bulk speed) for the interval 10:24102:8 UT, for three spacecraft (black: spacecraft 1; blue: spacecraft 3; green: spacecraft 4). Data for spacecraft 1 and 3 are provided by the CIS- 2 instrument, while data for spacecraft 4 are provided by the CIS-1 $\left(\mathrm{H}^{+}\right)$instrument. of the resulting dHT frame can be evaluated by fitting the single scatter plot of each GSE $X, Y, Z$ component of $\boldsymbol{E}_{c}$ versus the corresponding three components of the dHT electric field, $\boldsymbol{E}_{\mathrm{HT}}=-\boldsymbol{V}_{\mathrm{HT}} \times \boldsymbol{B}$. From the results reported in Table 1, it can concluded that: (a) a remarkably good agreement is found between $\boldsymbol{E}_{\mathrm{HT}}$ and $\boldsymbol{E}_{c}$, with fitting slopes $\sim 1$ and a very small least-square residual "quality factor" $D / D 0 \sim 0.01$; (b) for the three spacecraft, a good dHT frame exists and moves with a $\boldsymbol{V}_{\text {HT }}$ velocity similar for spacecraft 1 and 3, but smaller for spacecraft 4; (c) an $\boldsymbol{a}_{\mathrm{HT}}$ acceleration of the dHT frame can be noted, which introduces a small change in the $\boldsymbol{V}_{\mathrm{HT}}$ velocity between the beginning ( $\left.\boldsymbol{V}_{\mathrm{HT} 0}\right)$ and the end ( $\left.\boldsymbol{V}_{\text {HT_end }}\right)$ of the interval of interest.

\subsubsection{Validity of the Walén relation}

Next, the most powerful experimental test is to validate the Walén relation predicted by MHD for rotational discontinuities, i.e. the accelerated plasma flow is Alfvénic in the dHT frame, $\boldsymbol{V}-\boldsymbol{V}_{\mathrm{HT}}= \pm \boldsymbol{V}_{A}$. In spite of the simple conditions assumed (lack of experimental errors, time-stationarity, 1D structure, pure $\mathrm{H}^{+}$ion plasma), such a test works relatively well in most magnetopause crossings (Sonnerup et al., 1990, 1995; Phan and Paschmann, 1996; Phan et al., 1996, 2001). Scatter plots (not shown) between the individual $X, Y, Z$ (GSE) components of the plasma velocity $\left(\boldsymbol{V}-\boldsymbol{V}_{\mathrm{HT}}\right)$ in the dHT frame, and the corresponding components of the nominal Alfvén velocity

$\boldsymbol{V}_{A}=\boldsymbol{B}\left(\frac{1-\alpha}{\mu_{0} \rho}\right)^{1 / 2}$

(in SI units) during the same interval have been used to test the agreement of the data with the Walén relation. The pressure anisotropy

$\alpha=(\rho \|-\rho \perp) \frac{\mu_{0}}{B^{2}}$ 


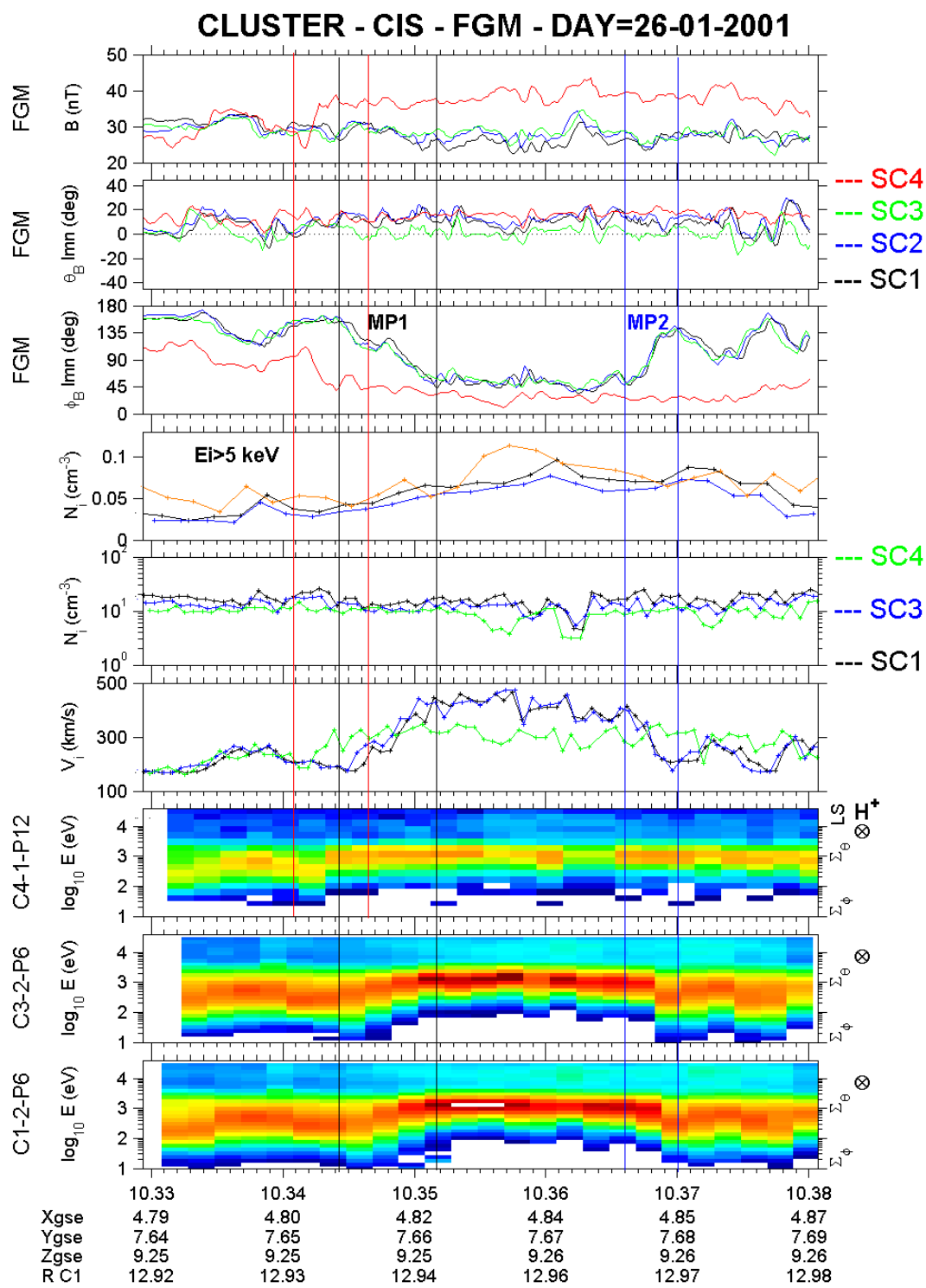

Fig. 6. Multi-spacecraft magnetic field and plasma data for the interval 10:33 10:38 UT. In the three first panels from top, the magnetic field strength (in $\mathrm{nT}$ ), the elevation angle $\theta_{B_{l m n}}$ and the magnetic field orientation $\varphi_{B_{l m n}}$ in the (LM) plane tangent to the magnetopause (averaged over $4 \mathrm{~s}$ ) are plotted. For each spacecraft, the $(L M N)$ frame used to plot magnetic field data is derived from the eigenvectors of the variance matrix of $B$. In the next three central panels the partial $(\geq 5 \mathrm{keV})$ ion densities, the total ion densities $N_{i}\left(\mathrm{~cm}^{-3}\right)$, and the total bulk flow speed are given. The 1D energy-time spectrograms provided by the CIS-2 instruments (spacecraft 1 and 3 ) and CIS-1 (spacecraft 4) are given in the three bottoms panels. and the total mass density, $\rho,\left(\rho=N_{i} m_{i}\right.$, assuming $95 \%$ of $\mathrm{H}^{+}$ions and $5 \%$ of $\mathrm{He}^{++}$ions) are averaged parameters evaluated over an adjacent interval, 10:37-10:38 UT. The scatter plots show an excellent agreement, and the magnitude of the slopes of the regression fit lines are $\sim 1$ for spacecraft 1 and 3 , regardless of the accelerating term, 0 or $\boldsymbol{a}_{\mathrm{HT}}$, introduced in $\boldsymbol{T}_{V_{H T}}$. In contrast, the quality of the fit is again poor in the case of spacecraft 4 , but some instrumental effects are suspected in the CIS-1 instrument (dead time effects when the count rate is large), resulting in an underestimation of the flow velocity. It can be concluded that the final change in velocity $\left(\boldsymbol{V}-\boldsymbol{V}_{\mathrm{HT}}\right)$ along the magnetic field direction is positive, of the order of the local Alfvén velocity $\boldsymbol{V}_{A}, \sim+150 \mathrm{~km} / \mathrm{s}$, as expected for a reconnection site located equatorward of Cluster. The same tests for the existence of a good dHT frame were performed on a majority of the accelerated flows evidenced during the 09:00-11:06 UT period, and agreed rather well with the Walén relation.

\subsubsection{Magnetopause motion}

We turn finally to an evaluation of the magnetopause motion along its normal, by using the most accurate normal directions, $\boldsymbol{n}_{E}$, derived from the variance analysis of $\boldsymbol{E}_{c}$, and the components of the frame velocity, $\boldsymbol{V}_{\mathrm{HT}}$. From the plasma moments and the field orientation, we anticipate an outward motion of the magnetopause (positive along $\boldsymbol{n}_{E}$ ) starting at $\sim 10: 34$ UT for spacecraft 4 (MP1 interval), followed by an inward (negative) motion (MP2 interval) starting at $\sim$ 10:36:40 UT. For each crossing, and from each satellite data set, different evaluations of the normal velocity, $\boldsymbol{V}_{H T} . \boldsymbol{n}_{E}$, of the magnetopause are summarized in Table 1, wih $\boldsymbol{u}_{n}$ and $\boldsymbol{u}_{n \_ \text {aver }}$ representing the averaged normal velocities, in the case of constant and accelerated frame velocities, respectively. For the magnetosheath-to-magnetosphere 
Table 1. Derived Magnetopause Parameters on 26 January 2001, 10:34:20-10:37:01 UT (See text for details)

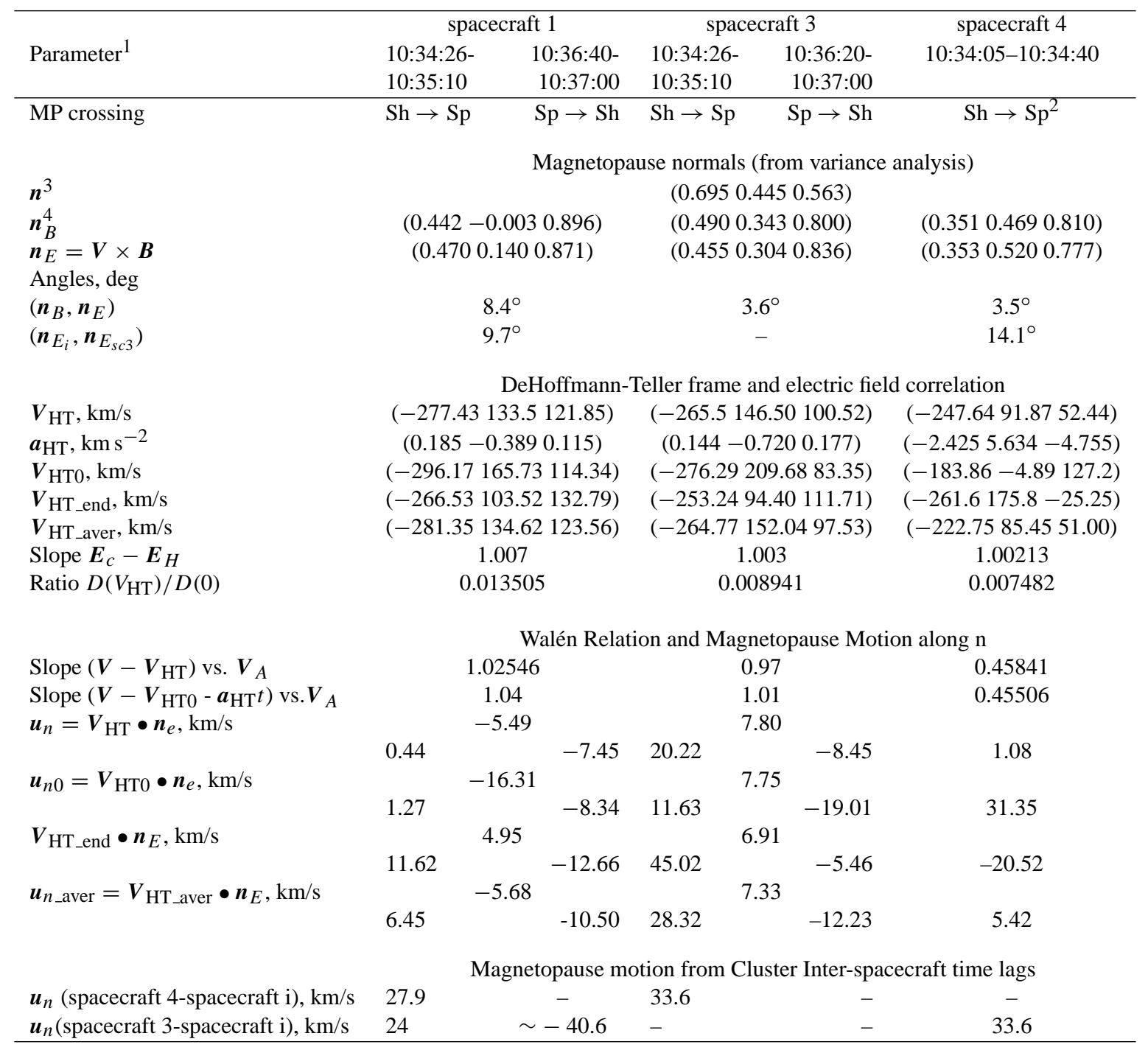

1 Vectors are given in GSE coordinates

${ }^{2}$ Outward moving magnetopause at $\sim 10: 37$ UT not detected by spacecraft 4

3 (Petrinec and Russell, 1996)

4 Magnetopause normal components at spacecraft 2 (from mvaB): (0.445 0.0600 .894$)$

crossing between 10:34:26 and 10:35:10 UT, all estimations of $\boldsymbol{u}_{n}$ (or $\boldsymbol{u}_{n_{-} \text {aver }}$ ) are, as anticipated, positive; $\boldsymbol{u}_{n}$ ranges between $+0.44 \mathrm{~km} / \mathrm{s}$ (spacecraft 1 ) and $+20.2 \mathrm{~km} / \mathrm{s}$ (spacecraft 3), and the equivalent $\boldsymbol{u}_{n_{-} \text {aver }}$ ranges between $+5.42 \mathrm{~km} / \mathrm{s}$ (spacecraft 4 ) and $+28.3 \mathrm{~km} / \mathrm{s}$ (spacecraft 3 ). It must be noted that $\boldsymbol{u}_{n}$ estimations are extremely sensitive to the associated normal direction. On the other hand, for the traversal between 10:36:40 and 10:37:00 UT, the normal magnetopause velocity, which is negative, ranges between -7.4 and $-12.2 \mathrm{~km} / \mathrm{s}$.

All of these single spacecraft evaluations of the magnetopause motion along its normal have been compared with a multi-spacecraft evaluation, by using the relative positions and timings of spacecraft 1,3 and 4 , assuming the magnetopause is a planar surface (Schwartz, 1998). The interspacecraft time lags lead to an averaged normal velocity, $\boldsymbol{u}_{n}$, of the order of $+24-+33 \mathrm{~km} / \mathrm{s}$ for the first MP1 crossing, and $-40 \mathrm{~km} / \mathrm{s}$ for the second crossing. These highly reliable inter-spacecraft evaluations are somewhat larger than those deduced from the single-spacecraft kinetic analysis; however, the outward velocity deduced from spacecraft 3 data is, for instance, comparable, $\sim+28-+30 \mathrm{~km} / \mathrm{s}$. It is known that there are several pitfalls in the single spacecraft methods, which are particularly sensitive to the selected data intervals (see, for more details, Khrabrov and Sonnerup, 1998). Our velocity evaluations at high-latitudes by the time delay 
technique are similar to those of ISEE $1 / 2$ at lower latitudes ( $<35^{\circ} \mathrm{GSM}$ ), 20-80 km/s (Berchem and Russell, 1982; Le and Russell, 1994).

\subsubsection{Magnetopause thickness}

We use the normal magnetopause velocities, $\boldsymbol{u}_{n}$, and the duration of the crossings to deduce the thickness of the different layers (current layer/boundary layer) encountered by the Cluster satellites during the outward-inward oscillatory magnetopause motion observed between 10:34:30 and 10:37 UT. For the MP1 crossing, the full magnetic field rotation across the current layer (or sheath transition layer) occurred in $\sim 40$ s for spacecraft 1 and 3 (10:34:30-10:35:10 UT), and in $\sim 30 \mathrm{~s}$ at spacecraft 4 . Using the velocities given in Table 1 , one obtains a thickness of $\sim 40 \mathrm{~s} \times 24 \mathrm{~km} / \mathrm{s} \sim 900 \mathrm{~km}$ (spacecraft 1 and 3 ) and $30 \mathrm{~s} \cdot 33 \mathrm{~km} / \mathrm{s} \sim 1000 \mathrm{~km}$ (spacecraft 4) for the MP current layer. For the MP2 traversal by spacecraft 1 and 3 , the thickness is of the same order, $24 \mathrm{~s} \times 40 \mathrm{~km} / \mathrm{s} \sim 900 \mathrm{~km}$. Our evaluations at highlatitudes, far from the subsolar region, are similar to the median thickness of the current sheet at the low-latitude magnetopause, $\sim 800 \mathrm{~km}$, (Berchem and Russell, 1982), whereas a thickness of $1500-2000 \mathrm{~km}$ is predicted by extrapolating the increase in thickness with the latitude. Thinner widths at low-latitudes were found for high $\beta$ conditions (Le and Russell, 1994), but the magnetosheath was very low, $\sim 0.6$, for this 26 January 2001 pass. The thickness of the high-latitude boundary layer (HBL), defined as the layer of enhanced plasma flow velocity, is more difficult to evaluate. If we assume that the magnetopause motion reverses at $\sim$ 10:35:50 UT, the HBL crossing lasted $\sim 70$ $80 \mathrm{~s}$ (10:34:30-10:35:50 UT and 10:35:50-1037 UT). By using constant normal velocities, one obtains $\sim 70-80 \mathrm{~s} \cdot 30$ $40 \mathrm{~km} / \mathrm{s} \sim 2100-3200 \mathrm{~km}$ for the HBL thickness, but this evaluation is surely underestimated.

\subsubsection{Velocity distributions}

D-shaped distributions predicted by Cowley (1982) are one of the most important kinetic signatures of reconnection. The velocity filter effect, resulting from the convection of the recently reconnected field line, introduces cutoffs in the velocity space that can be used to infer new information on the topology and location of the reconnection site (Gosling et al., 1991; Fuselier et al., 1991; Onsager and Fuselier, 1994). Figure 7 displays four successive slices of the distribution functions (time resolution: $12 \mathrm{~s})$ plotted in the $\left(v_{\|}-v_{\perp}\right)$ frame, for the accelerated flows detected at $\sim 10: 35$ UT by the spacecraft 1 and 3 . The distributions, which are basically identical for the two spacecraft, show the transmitted, accelerated $\mathrm{H}^{+}$magnetosheath population flowing along the magnetic field direction, but shifted in the $\boldsymbol{E} \times \boldsymbol{B}$ direction by $\boldsymbol{V}_{\mathrm{HT}} \perp$. They have the characteristic D-shaped form, with a low-energy cutoff at $+\boldsymbol{V}_{\mathrm{HT} \|}$ along the $+v_{\|}$direction. It can be noted that vectors superposed on the distribution functions in the $\left(v_{\|}-v_{\perp}\right)$ frame visualize the Walén relation
$\boldsymbol{V}-\boldsymbol{V}_{\mathrm{HT}}=+\boldsymbol{V}_{A}$, where $\boldsymbol{V}_{A}=150-200 \mathrm{~km} / \mathrm{s}$, is aligned with $\boldsymbol{B}$. Generally, in a steady case and at some distance from the reconnection site, such distributions are accompanied by a counterstreaming population of reflected magnetosheath ions, mirroring at lower altitudes in the ionosphere and returning to the spacecraft after convection dispersion (see Fuselier et al., 2000). Such a population is not present in our example, but the boundary is moving during this whole interval and precludes the detection of a reflected counterpart of the distribution.

\subsection{Flux transfer event (FTE) observed by Cluster}

Here we present an individual example of a FTE recorded on the same pass in order to demonstrate how the combination of plasma and magnetic field data provided by the Cluster multi-spacecraft mission can be used to determine the internal structure of such FTE tubes, either their geometrical (scale size, orientation) or their kinetic properties.

Detailed plots of magnetic field and plasma data for the FTE encountered around 11:31 UT are given in Fig. 8. The satellites were outbound in the afternoon magnetosheath. For the four spacecraft, the magnitude, the elevation, and the azimuth angles of the magnetic field expressed in the boundarynormal coordinate system, $(L M N)$, introduced by Russell and Elphic (1979), and based on the Petrinec and Russell (1996) model magnetopause, are plotted in the top three panels. The density of energetic ions $(>5 \mathrm{keV})$, the total density, the magnitude of the plasma flow, and three energy-time spectrograms for spacecraft 1,3 , and 4 are given below. Between $\sim 11: 30$ and $\sim 11: 32: 20 \mathrm{UT}$, for each spacecraft, the positive-negative bipolar pulse typical of the FTE is clearly identified in the profile of the elevation angle from the local tangential magnetopause surface, although more complex structures can be distinguished within the FTE tube. The total magnetic field (and the magnetic pressure, not shown) increases in the center of the event. The appearance of highspeed flows, up to $\sim 350 \mathrm{~km} / \mathrm{s}$, as well as the increase in the fluxes of high-energy magnetospheric ions, demonstrate that the four spacecraft are sampling the internal FTE open field tube. Another significant feature apparent inside the FTE is the deflection of the tangential magnetic field, measured by the angle $\varphi_{B_{l m n}}$, towards the magnetospheric direction. This deflection does not occur at the center of the event, at $\sim$ 11:31:10 UT, but is slightly time shifted.

\subsubsection{Flux tube orientation}

To extract the basic kinetic and geometrical properties of the FTE, we start by analyzing each set of spacecraft data, using the method adopted by Papamastorakis et al. (1989). the results are summarized in Table 2. First, we determine the orientation of the flux tube at each spacecraft, assuming this orientation is well predicted by the minimum variance direction, $\boldsymbol{k}_{\boldsymbol{B}}$, of the magnetic field (assuming the magnetic field strength remains constant throughout the event). In spite of the relatively large errors, the minimum variance analysis of 


\section{CLUSTER - DAY=26-01-2001 TM=1 Op-Mode=12 CIS2 - P6}
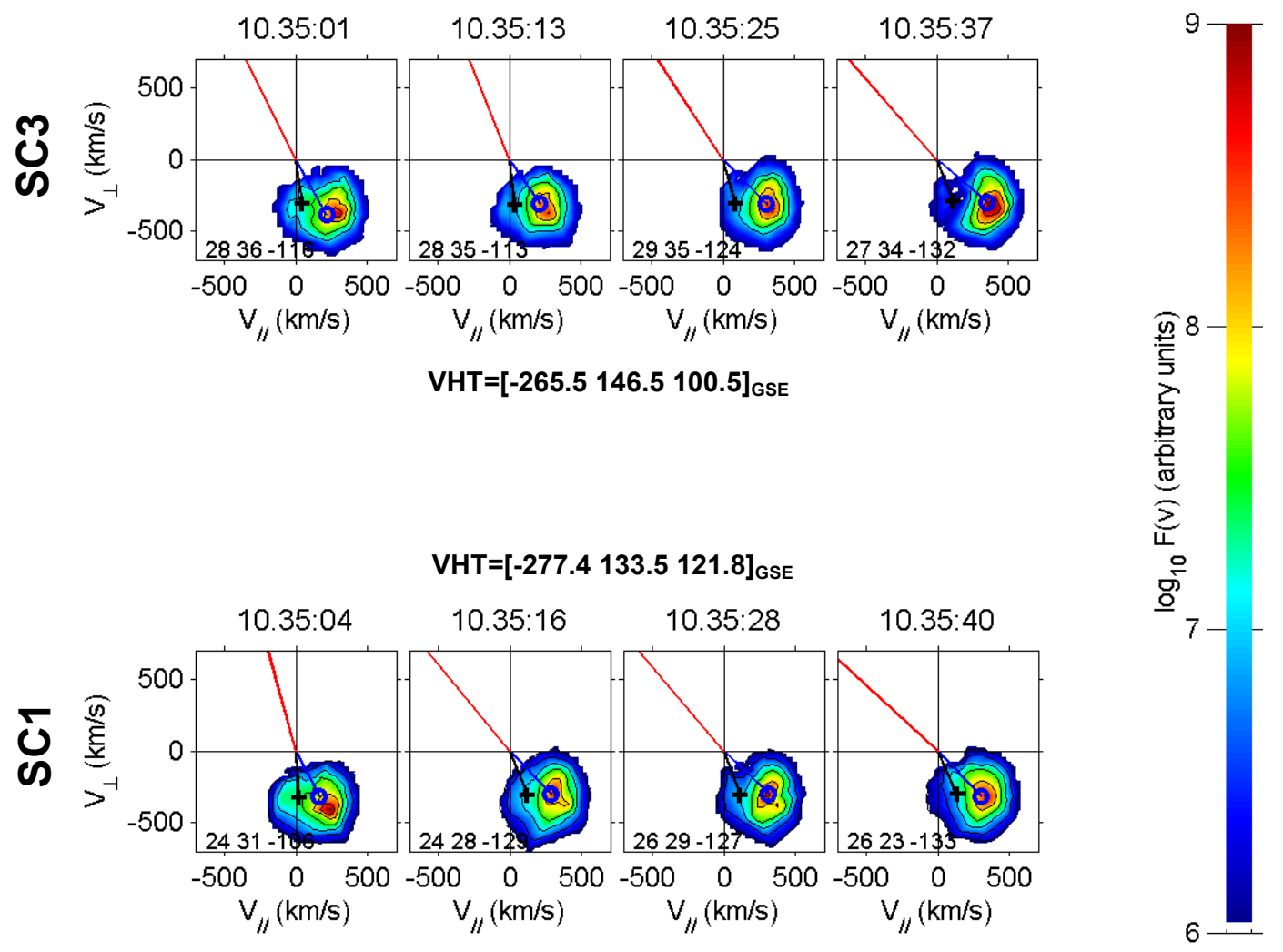

Fig. 7. Four successive slices of the distribution functions (time resolution: $12 \mathrm{~s}$ ) obtained by the CIS-2 instruments on spacecraft 1 (bottom row) and spacecraft 3 (top row) for the accelerated flows detected at $\sim 10: 35$ UT. Distributions are plotted in the $\left(v_{\|}-v_{\perp}\right)$ frame, where $v_{\|}$ is aligned with the local magnetic field and $v_{\perp}$ is the $(-\boldsymbol{V} \times \boldsymbol{B}) \times \boldsymbol{B}$ direction. The bulk flow velocity (o, blue) and $\boldsymbol{V}_{\mathrm{HT}}(+$, black) vectors are also plotted, as well as the Sun direction (red line).

the magnetic field for the data interval 10:30-10:33 UT gives similar directions at each spacecraft, with the angle between $\boldsymbol{k}_{\boldsymbol{B}}$, for spacecraft 3 (reference spacecraft), and other three spacecraft at only $4-6^{\circ} . \boldsymbol{k}_{\boldsymbol{B}}$ vectors lie near the tangential plane to the magnetopause, with their angle to the normal at around $12-18^{\circ}$. Moreover, the major component of the magnetic field, $\sim 28 \mathrm{nT}$, is along $\boldsymbol{k}_{\boldsymbol{B}}$.

\subsection{2 dHt velocity}

Second, the minimum variance analysis carried out on the convection electric field data, $\boldsymbol{E}_{c}=-\boldsymbol{V} \times \boldsymbol{B}$ at $4 \mathrm{~s}$ resolution ( $\boldsymbol{V}$ and $\boldsymbol{B}$ measured by the CIS and FGM instruments, respectively), gives a very well-defined minimum-variance direction, $\boldsymbol{k}_{\boldsymbol{E}}$, demonstrating that a very good moving dHT frame exists with a translating velocity vector, $\boldsymbol{V}_{\mathrm{HT}}$, which must be very close of the $\boldsymbol{k}_{\boldsymbol{E}}$ direction. $\boldsymbol{V}_{\mathrm{HT}}$ is evaluated by fitting the relationship between the three components of the convection electric field, $\boldsymbol{E}_{c}$, and the corresponding components of the $\boldsymbol{E}_{\mathrm{HT}}=-\boldsymbol{V}_{\mathrm{HT}} \times \boldsymbol{B}$ plot, similar to the previous magnetopause crossings. The resulting $\boldsymbol{V}_{\mathrm{HT}}$ vectors (associated with the slope of the $\boldsymbol{E}_{c}-\boldsymbol{E}_{\mathrm{HT}}$ regression line) and the "quality factor", $D / D(0)$, are also given in Table 2 . They are practically similar for spacecraft 1 and 3 and, as anticipated, are nearly aligned with $\boldsymbol{k}_{\boldsymbol{E}}$. The obtained $\boldsymbol{V}_{\mathrm{HT}}$ velocities are rather similar to the $\boldsymbol{V}_{\mathrm{HT}}$ obtained for the magnetopause crossings on this pass (see Table 1). For spacecraft 4 the $\boldsymbol{V}_{\mathrm{HT}}$ vector direction remains the same, but differs in magnitude under the combined effects of a slightly different magnetic field and velocity profiles (see Fig. 8).

\subsubsection{Walén test}

New information is gained by analyzing the Walén relationship, $\boldsymbol{V}-\boldsymbol{V}_{\mathrm{HT}}= \pm \boldsymbol{V}_{A}$. The Walén relation is approximately satisfied for spacecraft 1 (positive slope $=0.87$ ), but this slope is somewhat less for spacecraft $3(\sim 0.663)$, and even $\sim 0.45$ for spacecraft 4 . Nevertheless, in all cases, $\boldsymbol{V}-\boldsymbol{V}_{\mathrm{HT}}$ is nearly parallel to the magnetic field $\boldsymbol{B}$ and the magnitudes are positively related, as anticipated for a reconnection site equatorward of the satellites.

\subsubsection{Motion of the FTE tube}

Before discussing the motion and size of this event, we plot, in Fig. 9, the projection of all the vectors $\left(\boldsymbol{k}_{\boldsymbol{B}}, \boldsymbol{V}_{\mathrm{HT}}\right.$, magnetic 


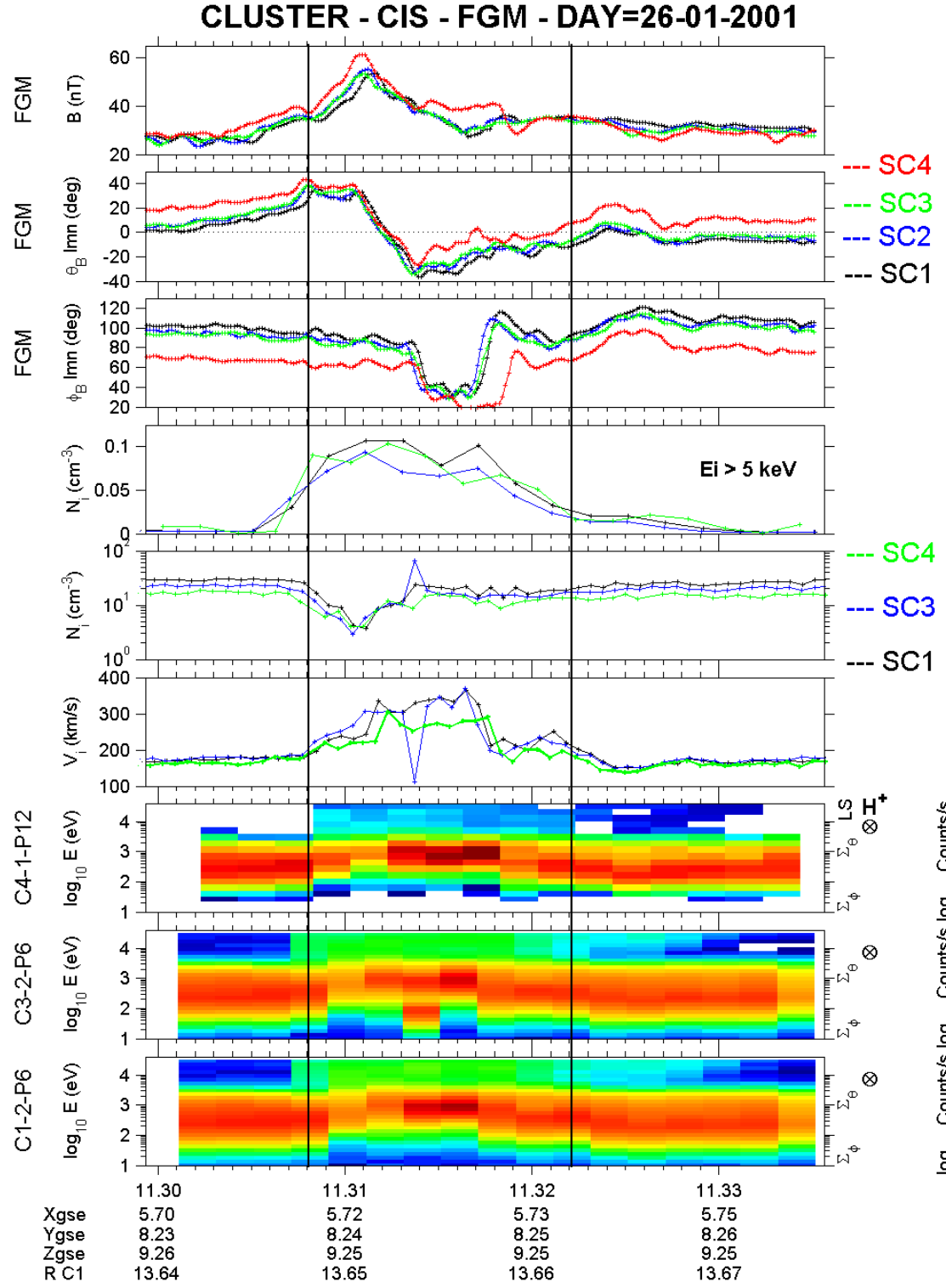

Fig. 8. Overview of Cluster plasma and magnetic field measurements during the flux transfer event detected around 11:31 UT on 26 January 2001. The magnetic field data are shown in the top three panels: magnetic field strength $B$ (nT), magnetic field elevation and azimuth angles, $\theta_{b_{l m n}}$ and $\varphi_{B_{l m n}}$, in $(L M N)$ boundary normal coordinates. The GSE components of the normal direction are $(0.7160 .452$ 0.530 ) and were calculated using the Petrinec and Russell (1995) model. In the following panels the number density of energetic ions $\left(E_{i}>5 \mathrm{keV}\right)$, the total ion density $N_{i}\left(\mathrm{~cm}^{-3}\right)$, and the plasma bulk velocity $V_{i}(\mathrm{~km} / \mathrm{s})$ are shown. 1D energy-time ion spectrograms obtained by the CIS-2 (spacecraft 1 and 3) or the CIS-1 (spacecraft 4) instruments are given in the bottom panels, with the GSE coordinates of spacecraft 1 . field, plasma flow velocities) in the ( $L M)$ plane tangential to the magnetopause. The $\boldsymbol{k}_{\boldsymbol{B}}$ direction, anticipated as a reasonably good predictor of the FTE axis direction (Walthour and Sonnerup, 1995), does not coincide with the magnetosheath magnetic field direction and the direction taken by the magnetic field within the tube. Indicated by the $\varphi_{B}$ rotation in Fig. 8, this tilt can be interpreted as a field twisting about the tube axis (Saunders et al., 1984). From the diagram, it can be also concluded that the FTE flux tube is convecting northeastward (in the $L M$ Plane) with a velocity $\boldsymbol{V}_{\mathrm{HT}}$ evaluated to be about $\sim 190-220 \mathrm{~km} / \mathrm{s}$ for spacecraft 1 and 3 . This velocity is certainly higher than the perpendicular component of the ambient flow, so that the FTE flux tube is not exactly convecting with the ambient flow. The same diagram, where the $(L M)$ positions of the four Cluster spacecraft (spacecraft 3 is centered on the origin) are also represented, can be very useful in determing the reliability of the predictions of the kinetic analysis concerning the tube axis direction and its motion, compared to the direct inter-spacecraft measurements. From Fig. 7, it can be seen that at around 11:31:04 UT, the sequence of entry is first spacecraft 3-spacecraft 2 (almost simultaneously at the magnetic field data resolution of $1 \mathrm{~s}$ ), then spacecraft 4 (with a delay $<1 \mathrm{~s}$.), then spacecraft 1 , with a delay of $2-3 \mathrm{~s}$. From the plasma velocity profiles, the delay between spacecraft 3 and 1 is of the order of the CIS time resolution, i.e. $4 \mathrm{~s}$. By knowing the satellite relative positions, it can be concluded that the exact FTE axis is nearly aligned with the spacecraft 3 -spacecraft 2 line and does not coincide with the $\boldsymbol{k}_{\boldsymbol{B}}$ directions found by the minimum variance analysis. Such a difference of $\sim 5-10$ degrees is anticipated in the case of the encounter with a 2D structure and could be evaluated by using more sophisticated methods (Walthour and 
Table 2. Derived FTE Parameters on 26 January 2001, 11:30-11:33 UT

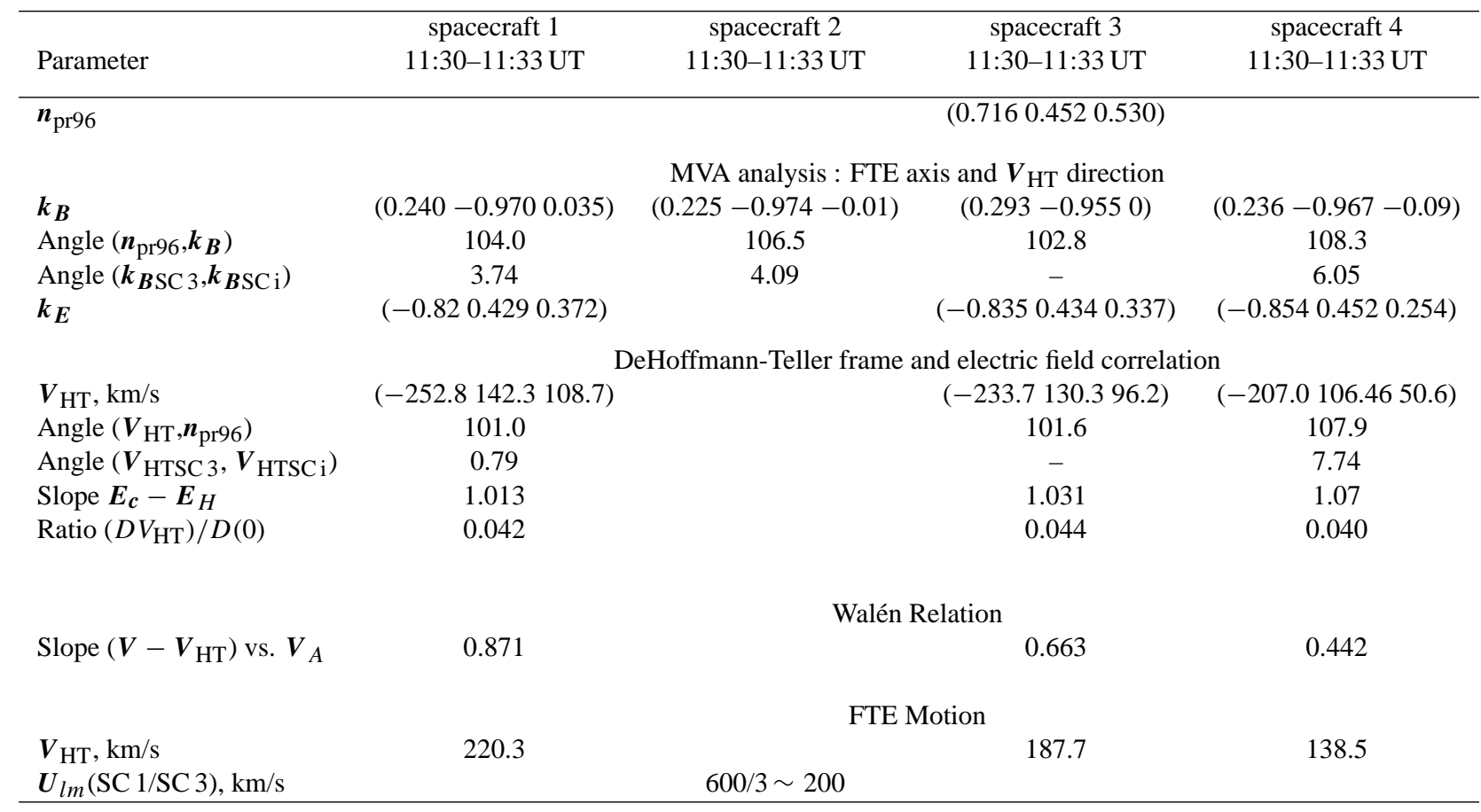

Sonnerup, 1995). Moreover, the tube convecting velocity, $u_{l m}$, evaluated from the time lags, is of the order of $200 \mathrm{~km} / \mathrm{s}$ at the entry, comparable to the $\boldsymbol{V}_{\mathrm{HT}}$ component.

\subsubsection{Size of the FTE tube}

Finally, the total diameter of the FTE tube parallel to the magnetopause can be estimated to be $80 \mathrm{~s} \times 200 \mathrm{~km} / \mathrm{s} \sim 16000 \mathrm{~km}$, of the order published, for instance, by Saunders et al. (1984). Within this tube, the diameter of the region where the magnetic field rotates is concentrated to $20 \times 20=8000 \mathrm{~km}$, presumably due to a core central current, and the region of accelerated flow has a diameter of $\sim 12000 \mathrm{~km}$. Finally, we notice that the FTE internal structure is certainly more complicated, as revealed by the shifted observations made by spacecraft 4 located $\sim 500 \mathrm{~km}$ from the $(L M)$ plane, or by a low-energy plasma jetting observed by spacecraft 3 in the center of the tube (see Fig. 7, spectrogram panel C3). Moreover, magnetopause motions along the normal are not negligible; an inward motion of the magnetopause of the order of $\sim 50-70 \mathrm{~km} / \mathrm{s}$ can be deduced from the dHT analysis and could result in a sharp increase in the field tilting that is observed later after the polarity change of the normal field.

\section{Second case study: 2 February 2001, Northward IMF}

This Cluster outbound pass in the northern afternoon side of the magnetosphere (Fig. 10) is of special interest as it is the first to occur under northward IMF- $B_{Z}$ conditions. For this event, another paper in the present issue of Annales Geophysicae is devoted to ground-based radar signatures (Pitout et al., 2001) and convection cells at low altitudes.

We determined from ACE observations upstream of the bow shock near the L1 point at $\sim 220 R_{E}$ (Fig. 11), and WIND observations on the duskside of the magnetosphere but far away $\left(Y_{\mathrm{GSE}} \sim 200 R_{E}\right)$, that the IMF during this event was fluctuating, directed primarily northward (IMF$\left.B_{Z} \sim 3-4 \mathrm{nT}\right)$ for a large interval (09:05-15:00 UT). This includes the Cluster cusp observations for 2 February 2001, except for a short IMF- $B_{Z}<0$ incursion around $\sim 11: 30$ and 12:20 UT. Strongly directed duskward before 09:10 UT, IMF- $B_{Y}$ started 40-min periodic dusk-dawn fluctuations ( $4 \mathrm{nT}$ peak-to-peak), with most being positive $\left(B_{Y} \sim 2-\right.$ $3 \mathrm{nT}$ ) between $\sim 11: 00$ and 12:00 UT. Therefore, from these data, we expect a high magnetic shear near the duskward northern magnetopause around 10:00-10:30 UT, when Cluster crossed the cusp during its duskward outbound pass; thus, conditions are very favourable for reconnection in this region (Crooker, 1979; Luhmann et al., 1984). On the other hand, the solar wind dynamic pressure, given in the bottom panel of Fig. 11, remained relatively steady and near its nominal value, around $1-1.2 \mathrm{nPa}$ for the 08:00-12:00 UT interval.

\subsection{CIS and FGM data}

Figure 12 shows an overview of the relevant FGM magnetic field data and CIS ion data gathered during the 08:0016:00 UT interval on 2 February 2001, in the form of mag- 


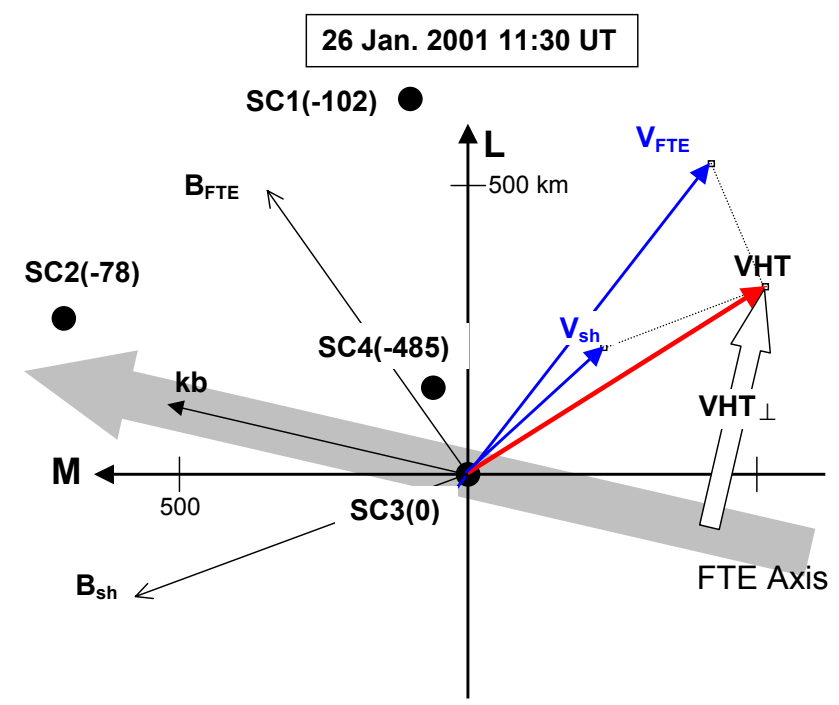

Fig. 9. Diagram representing in the magnetopause tangential $(L M)$ plane: (a) the vectors resulting from the spacecraft 3 data analysis, deHoffmann-Teller velocity, $\boldsymbol{V}_{\mathrm{HT}}$, ambient plasma flow, $\boldsymbol{V}_{s h}$, accelerated plasma flow, $\boldsymbol{V}_{\mathrm{FTE}}$, ambient magnetosheath magnetic field direction, $\boldsymbol{B}_{s h}$, internal (twisted) magnetic field direction, $\boldsymbol{B}_{\mathrm{FTE}}$, (b) the positions of the four Cluster satellites, at 11:30 UT, relative to the spacecraft 3 position (scale in $\mathrm{km}$, distance to $L M$ plane between brackets). The flux tube axis (large gray arrow) is the minimum variance direction, $\boldsymbol{k}_{\boldsymbol{B}}$, of the magnetic field. The FTE motion, indicated by the open arrow labeled $V_{\mathrm{HT} \perp}$, carries the flux tube across the four Cluster satellites (see text for details).

netic field strength, angles, partial density (at $E_{i} \geq 3 \mathrm{keV}$ ), and full moments $(N, V, T)$ calculated on board from the full 3D distributions and the one spectrogram provided by the CIS-2 instrument on the spacecraft 3 "reference" spacecraft, as functions of time and GSE spacecraft 3 position. Note that throughout the 08:00-12:00 UT period, the Cluster magnetic field orientation retained the characteristics of the high-latitude magnetospheric magnetic field in this duskside sector, i.e. pointing $-40^{\circ}$ in elevation $(\theta)$ and dawnward at $-100^{\circ}$ in azimuth $(\varphi)$ at 10:00 UT.

Major regions and boundaries can easily be identified during this time interval. Starting at 08:00 UT, the regions successively crossed by Cluster were: (a) the polar cap, up to 08:50 UT; (b) from $\sim 08: 50$ to $\sim 09: 40 \mathrm{UT}$, the highlatitude $\left(Z_{\mathrm{GSE}} \sim 8 R_{E}\right.$ ) plasma mantle; (c) from $\sim 09: 40 \mathrm{UT}$ to $\sim 10: 40 \mathrm{UT}$, the exterior cusp, followed by the entry layer characterized by entries of low-energy magnetosheath ions on closed field lines; (d) from $\sim 11: 20$ UT to 13:25 UT, Cluster stayed on closed field lines and the CIS instrument detected only high-energy trapped ions; (e) preceded by a partial crossing of the entry layer between $\sim 13: 25 \mathrm{UT}$ and 14:50 UT, the Cluster spacecraft crossed the magnetopause and entered the magnetosheath around 14:40 UT. Multiple MP crossings were induced by the changes in the IMF orientation until the definitive MP traversal at around 15:10 UT. In this paper, we concentrate on the first part of the pass, i.e. within the cusp. A detailed study of the 2 February 2001

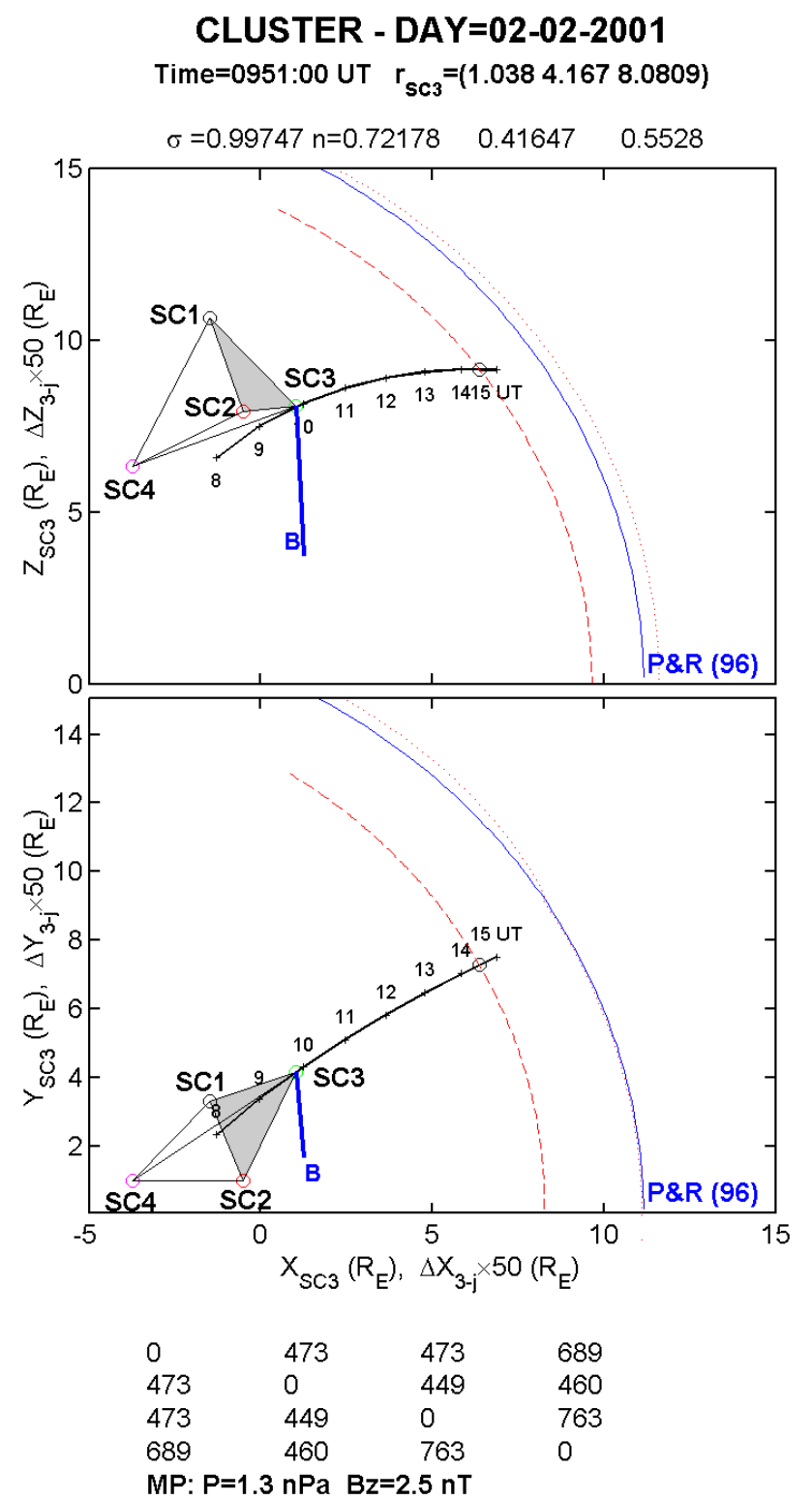

Fig. 10. Cluster spacecraft 3 orbit on 2 February 2001, from 08:00 to 15:00 UT, projected onto the $X-Y$ (bottom) and $X-Z$ (top) GSE planes. The relative configuration of the Cluster tetrahedron at 09:51 UT, centered on the spacecraft 3, is also mapped. For clarity, the inter-spacecraft distances have been multiplied by a factor of 50 . The solid and dotted lines give cuts in the $Y=0$ (top) and $Z=0$ (bottom) planes of: (a) the model magnetopause location (Petrinec and Russell, 1996) for IMF- $B_{Z}=+2.5 \mathrm{nT}$ and $P_{s w}=1.3 \mathrm{nT}$ (solid line); (b) the scaled magnetopause when spacecraft 3 traverses the magnetopause at $\sim 14: 30$ UT (dotted line); the scaling factor is 0.997. $Y=Y_{\mathrm{sc} 3}$ and $Z=Z_{\mathrm{sc} 3}$ magnetopause cuts at 14:30 UT are also plotted (dashed lines). The direction of the magnetic field measured by spacecraft 3 at 09:51 UT is also given.

magnetopause crossings is deferred to future papers.

Before discussing the cusp crossing itself, we introduce Fig. 13, which gives a three-spacecraft view of the event, including the mantle part. Energy-time spectrograms for 


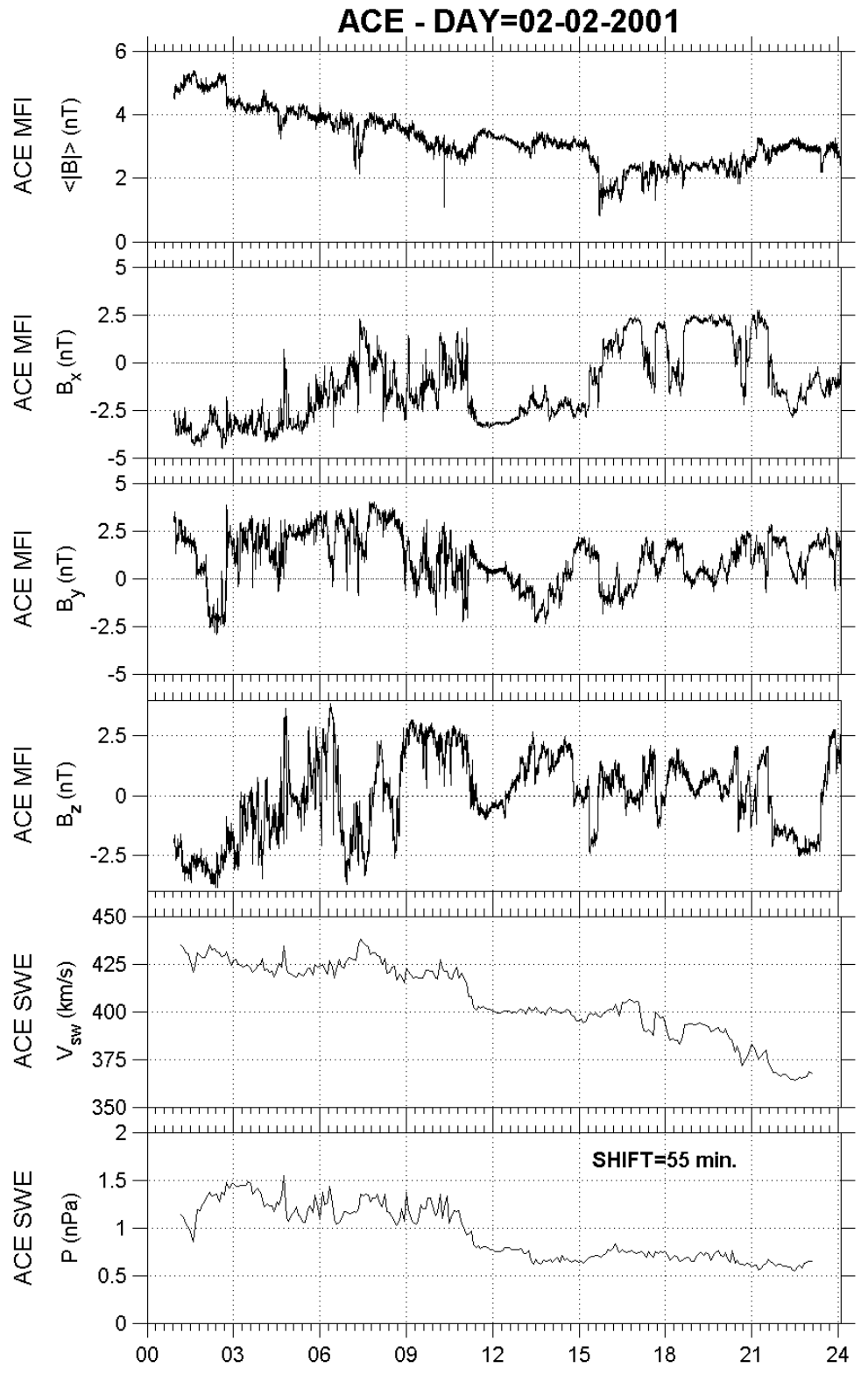

Fig. 11. ACE interplanetary magnetic field (strength and 3 GSE components), solar wind bulk speed and dynamical pressure for 2 February 2001. ACE data have been shifted by a propagation delay of $55 \mathrm{~min}$ to take into account the transit time between the $\mathrm{L} 1$ point and the Earth's magnetopause.

spacecraft 1,3, and 4 are displayed in the three bottom panels for the 08:45-10:30 UT time interval, and blowup views of the density and average energy during the 09:30-10:00 UT interval are given in the two top panels for the three spacecraft. Concentrating first on the three spectrograms, a significant time lag is clear between the times that the three satellites encountered the first mantle patch. CIS on the leading spacecraft 3 detected the first higher ion flux region at $\sim$ 08:49 UT, followed $\sim 200 \mathrm{~s}$ later by spacecraft 1 , and a detection by spacecraft 4 ends $150 \mathrm{~s}$ after that by spacecraft 1 . To explain this time lag, we show in Fig. 10 the relative position of the three satellites in GSE coordinates, using spacecraft 3 as the reference satellite. The successive time lags roughly correspond to the delays expected in the $X-Y$ plane for satellites that cross in the sequence $(3,1,4)$, with a quasi- stagnant boundary at $V_{s c} \sim 2 \mathrm{~km} / \mathrm{s}$. The same order and time delays are apparent at the exit of the latest plasma mantle at $\sim$ 09:20 UT.

Judging from the obvious jump in density (Fig. 13, top panel), the Cluster satellites entered the high-latitude cusp at $\sim 09: 45$ UT. The clear time lags separating the 3 spacecraft are highlighted in the panel by 3 successive vertical lines in the sequence $(3,1$, and 4$)$. spacecraft 3 is the first to cross the cusp poleward boundary, followed $\sim 80$ s later quasi-simultaneously by spacecraft 1 and 4 . From their respective positions and the direction of the local magnetic field lines (vector direction plotted in Fig. 10), we may infer that the cusp boundary is motionless or slowly moving perpendicularly to the local magnetic field. 
CLUSTER - CIS - FGM - DAY =02-02-2001

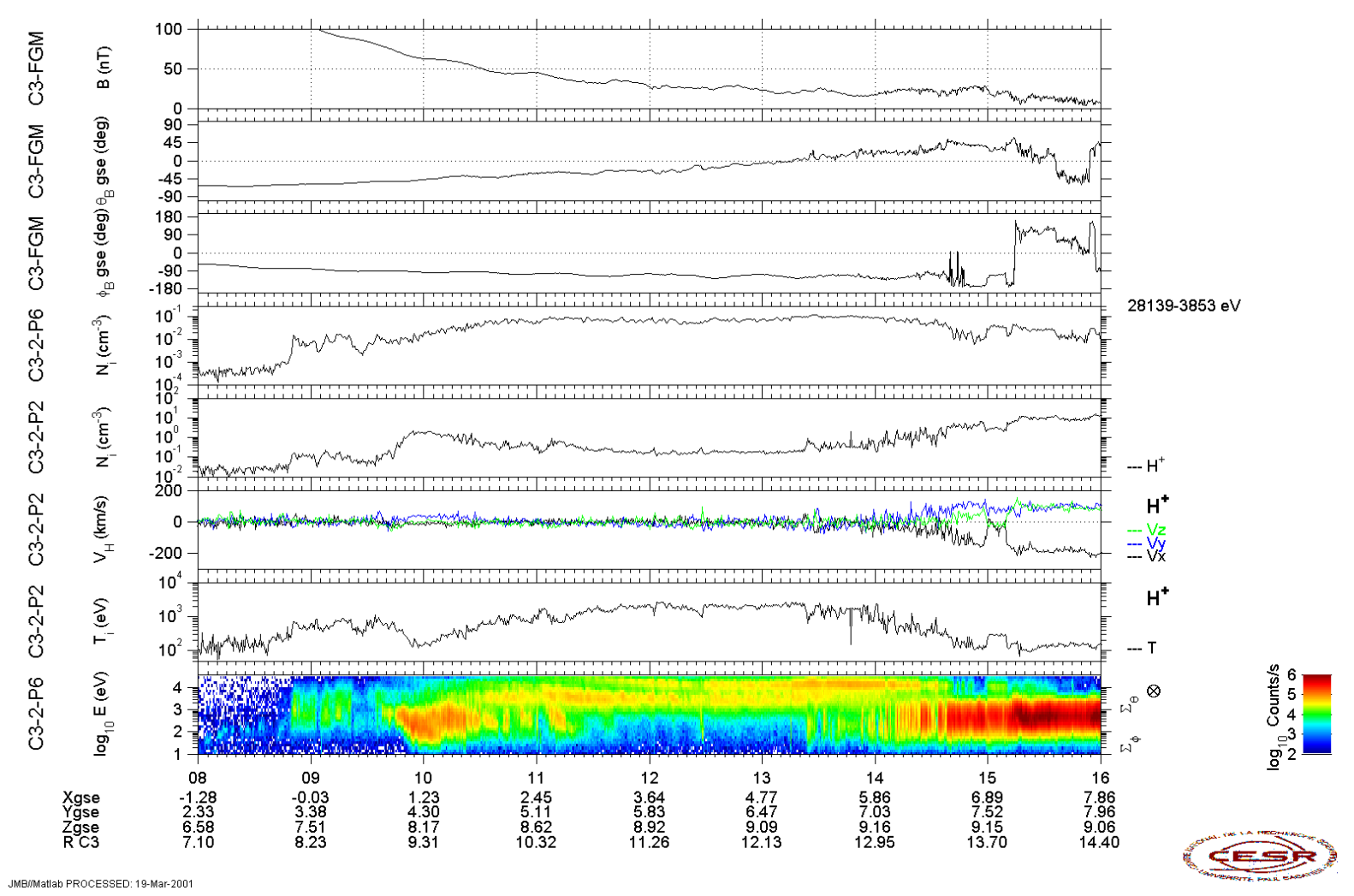

Fig. 12. Plasma and magnetic field data from Cluster/spacecraft 3, FGM, and CIS instruments, for the 08:00-16:00 UT time interval during the high-latitude crossing on 2 February 2001. See Fig. 2 for details.

\subsection{Possible merging signatures}

As IMF- $B_{Z}$ was directed steadily northward for at least 40 min before the cusp crossing by Cluster, we try to identify in Fig. 13 the possible signatures of merging between the IMF and the lobe field lines. One of the most direct and measurable indicators of reconnection for IMF- $B_{Z}>0$ should be a reversed plasma flow, from anti-sunward to sunward. Up until now, just a few studies have addressed the high-latitude cusp regions for northward IMF (Gosling et al., 1991; Kessel et al., 1996; Chen et al., 1997; Fuselier et al., 2000). Returning briefly to Fig. 12, we note that the flow within the cusp remained very low, but was anti-sunward directed, with a relatively increasing $+V_{y}$ duskward component. This suggests that the Cluster spacecraft encountered the interior cusp, as defined by Chen et al. (1997), and not the exterior cusp.

\subsubsection{Energy-dispersed structures}

Although indirectly, another typical signature of reconnection between a northward-directed IMF and open field lines in the lobes is the characteristic large-scale, reverse, energylatitude dispersion observed at low- and mid-altitudes near the poleward boundary of the cusp (Reiff, 1984; Escoubet and Bosqued, 1989; Lundin et al., 1991). Magnetosheath- like (solar wind) ions entering the presumed reconnection region poleward of the satellite are dispersed by $\boldsymbol{E} \times \boldsymbol{B}$ convection (directed mostly sunward) and by time-of-flight effects.

A number of "reverse" energy dispersed structures can be easily recognized in the three spectrograms plotted in Fig. 13, and confirmed by the average energy profiles plotted in the second panel (from top). A number of "saw tooth" structures are evident, with a gradual decline in ion energy with increasing time (or $X_{\mathrm{GSE}}$ ). The two most obvious decreases, marked by vertical lines, start at $\sim 09: 50 \mathrm{UT}$ (these are clearer in spectrograms C1 and C4) and 09:55 UT. Lockwood and Smith $(1992,1994)$ have demonstrated that temporal variations in the reconnection rate (pulsed reconnection) can generate such step-like discontinuities in the dispersions. A more accurate examination of the flow profile (not plotted) during this "saw tooth" series indicates flow enhancements directed into the magnetosphere $\left(V_{z}<0\right)$ and associated with the start of injected bursts, which were simultaneously seen by the three spacecraft, but were more intense for spacecraft 1 and 4. A noticeable, although small, turning in the $V_{y}$ convection direction (from duskward to dawnward directed) can also be seen within the enhanced flow bursts. Thus, the prevailing direction of these burst flows is not really that of the tailward/duskward flow observed in the magnetosheath (e.g. after 15:10 UT), but instead, a rather stagnant perpen- 


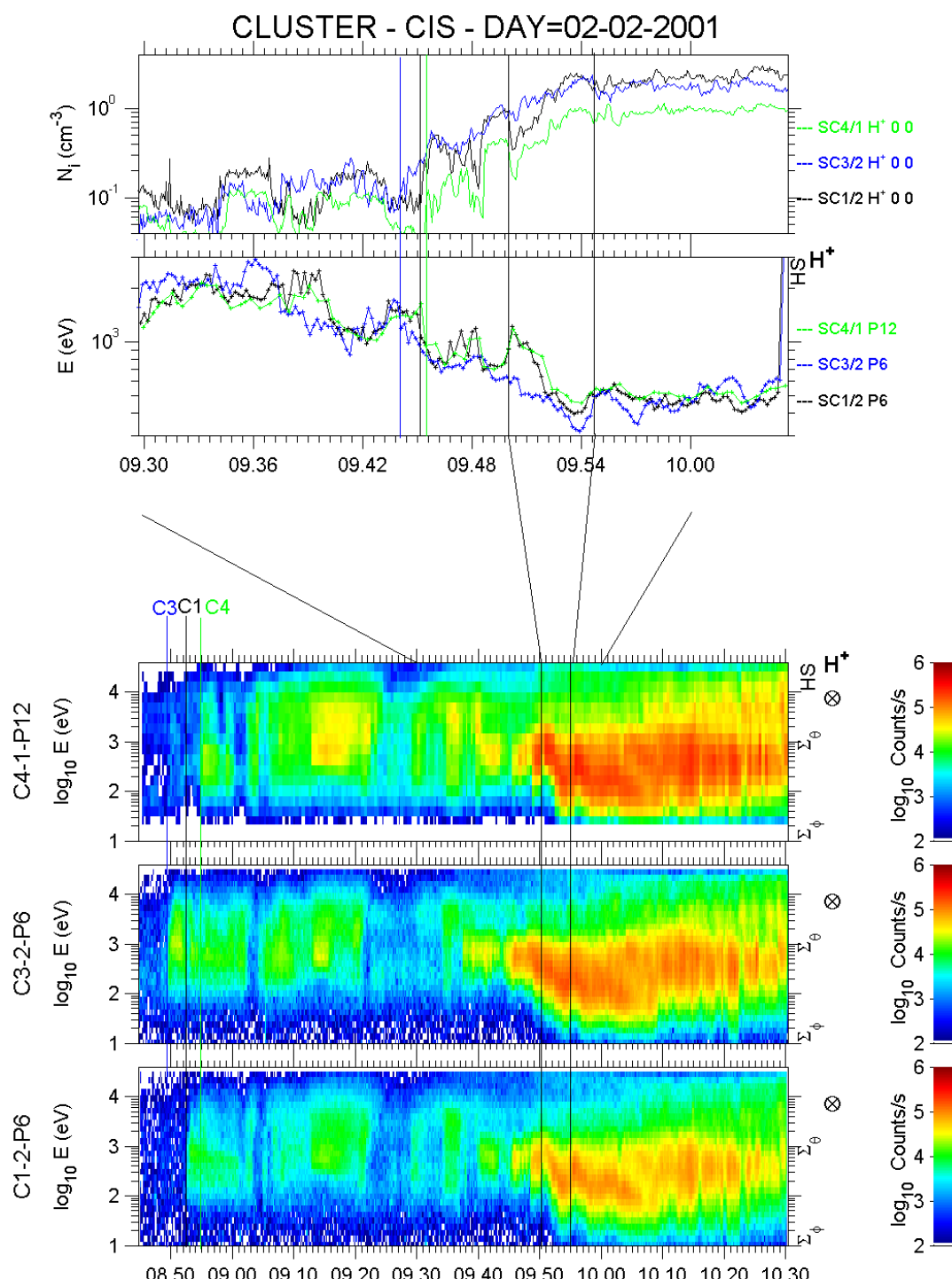

Fig. 13. Three-spacecraft view of the event, including the mantle part. Energy-time spectrograms for spacecraft 1,3 , and 4 are displayed in the three bottom panels for the 08:4510:30 UT time interval, and enlarged views of the density and average energy during the 09:30-10:00 UT interval are given in the two top panels, for the three spacecraft. dicular flow.

\subsubsection{Ion distributions}

To describe these injections more precisely, Fig. 14 shows successive 2D $\left(v_{\|}-v_{\perp}\right)$ contour plots of the $\mathrm{H}^{+}$distribution functions for the first injection event observed at $\sim$ 09:50:30 UT by spacecraft 1 (distributions obtained by spacecraft 3 are similar). Starting at $\sim 09: 50: 55$ UT, the first three distributions are D-shaped distributions flowing predominantly along the $+V_{\|}$axis (along the field). The velocity in the perpendicular direction is too small to be shown in these plots, with a noticeable cutoff in the magnetic field direction (pointing Earthward) evolving from $\sim+100 \mathrm{~km} / \mathrm{s}$ to smaller values. Such low-speed cuts arise from velocity filter effects (Onsager and Fuselier, 1994) that are anticipated for ions recently injected from a reconnection site on recently open field lines connected by one end to the Earth. Part of the distribution in the antiparallel direction $\left(V_{\|}<0\right)$ is al- most empty of magnetosheath $(\leq 200 \mathrm{~km} / \mathrm{s})$ ions, but contains very weak fluxes of high energy ions. Generally, a counterstreaming population of reflected magnetosheath ions accompanies such distributions. These ions mirror at lower altitudes in the ionosphere and possibly return to the spacecraft after convection dispersion (see Fuselier et al., 2000), as long as perpendicular convection is not too strong during the $\sim 10$ min of travel time. In our case, the low-speed cutoff for mirroring ions is not present, and thus, it is difficult to estimate the field-aligned distance from the spacecraft to the reconnection site. However, we can definitely conclude that the reconnection site is poleward (at higher latitudes) of the spacecraft since the primary ions are flowing Earthward in the magnetic field direction. Later, after 09:51:43 UT, distributions keep their D-shape but the cut evolves toward small, negative values. Recently, Fedorov et al. (2000) analyzed the Interball-Tail satellite measurements and observed D-shaped distributions with similar, positive and negative cuts in the 


\section{CLUSTER - SC1 - DAY=02-02-2001 TM=1 Op-Mode=9 CIS1 - P12}

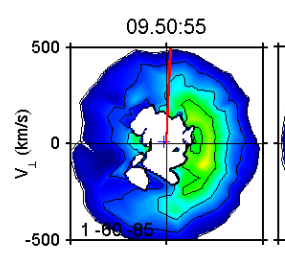

09.51:11

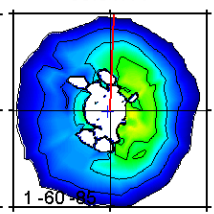

09.52:15

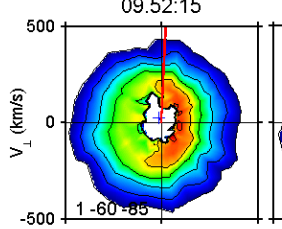

$09.52: 31$
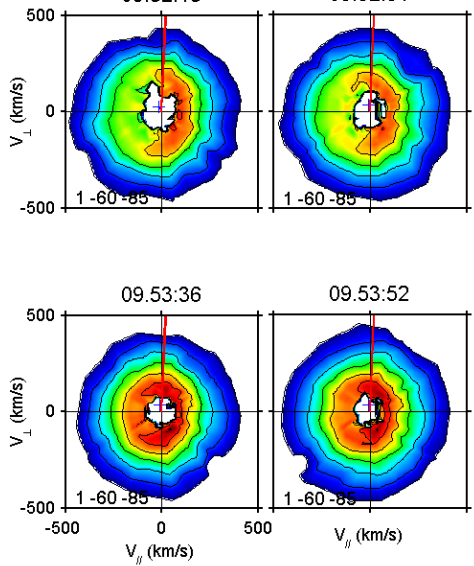

09.53:52

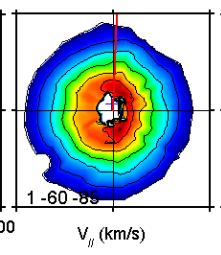

$09.51: 27$

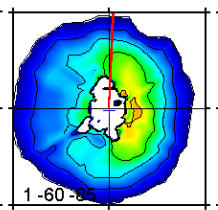

09.52:47

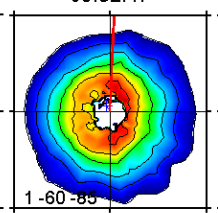

09.54:08

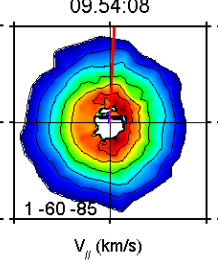

$09.51: 43$

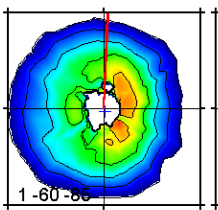

09.53:03

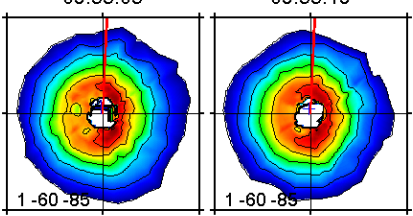

09.54:24

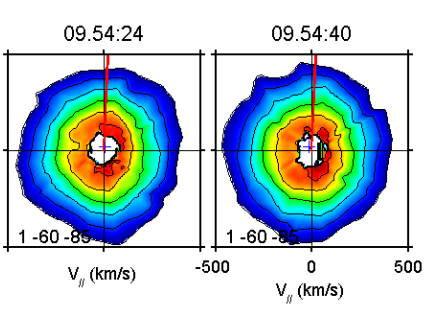

09.51:59

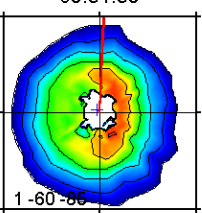

09.53:19

$1-60-8$
$\mathrm{H}^{+}$

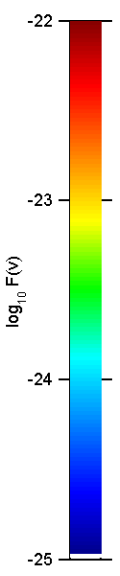

Fig. 14. Successive ion distributions provided by the CIS-1 instrument on Cluster/spacecraft 1, for the 4-min interval corresponding to the first dispersed cusp injection. Distributions accumulated during $16 \mathrm{~s}$ ( 4 spin periods) are plotted in the $\left(v_{\|}-v_{\perp}\right)$ frame, where $v_{\|}$is aligned with the local magnetic field and the cut plane contains the $+X_{\mathrm{GSE}}$ axis (red).

high-latitude cusp.

More interesting, trapped magnetosheath ions appear at 09:51:59 UT, followed after 09:52:15 UT by distributions characterized by an additional and intense population of magnetosheath-like ions mirroring at lower intermediate altitudes. However, the clear minimum observed in the $-V_{\|}$ outgoing direction implies that ions are definitively streaming down to the ionosphere and are lost.

The reconnection site must be duskward of Cluster since the observed flow spikes are preferentially directed dawnward $\left(-V_{y}\right)$. Assuming an Alfvén speed of the order of $150 \mathrm{~km} / \mathrm{s}$ and a magnetosheath flow of the same order, a small dawnward/sunward convective flow can be expected from Walén relation (Chen et al., 1997). Newly-reconnected field lines extend either sunward through the cusp or tailward of the reconnection site through the plasma mantle. This convection would result in a dawnward-directed convection in the polar cap at the feet of field lines connecting Cluster to the polar ionosphere in the duskward auroral sector. Such convection was effectively observed by EISCAT around 10:00 UT during the same event (Pitout et al., 2001, this issue), and strongly validates our Cluster observations.

To summarize, this cusp crossing during a period of northward IMF- $B_{Z}$ demonstrates that sporadic injections of magnetosheath ions occur at the poleward boundary of the high altitude cusp, presumably originating from a reconnection site located duskward/poleward of the Cluster satellites.
Multiple enhanced flows, separated by $\sim 5 \mathrm{~min}$, and primarily directed downward (with a small dawnward component) are clearly observed simultaneously by three satellites and demonstrate the sporadic nature of the reconnection process. Relatively isotropic distributions are also observed, with a population of locally trapped ions. More detailed studies of the distributions correlated with wave turbulence will be carried out in future planned Cluster studies.

Acknowledgement. We wish to acknowledge all the scientific and technical personnel at CESR/CNRS, Toulouse; UNH, Durham; IFSI, Frascati; UCB, Berkeley; MPI Garching; MPAE, Lindau; UW, Seattle; and ISP, Kiruna; for their invaluable contribution of performing long and exacting job of defining, assembling, and calibrating the CIS instruments for the Cluster missions. The first author expresses his personal thanks to C. Aoustin, CIS Project Manager, for his exceptional and devoted work. The work at CESR is supported by CNES (French Space Agency). We thank P. Décréau for providing WHISPER density data, the CDAWeb at GSFC for supplying the ACE key parameters and survey data, and N. Ness (Bartol Research Institute) for providing the ACE_MFI magnetic field data. We thank the referees for their positive comments.

Topical Editor G. Chanteur thanks P. J. Cargill and another referee for their help in evaluating this paper. 


\section{References}

Balogh, A., Dunlop, M. W., et al.: The Cluster magnetic field investigation, in: The Cluster and Phoenix Missions, (Eds) Escoubet, C. P., Russell, C. T., and Schmidt, R., 65-92, Kluwer Acad. Publishers, Dordrecht, the Netherlands, 1997.

Berchem, J. and Russell, C. T.: The thickness of the magnetopause current layer: ISEE-1 and -2 observations, J. Geophys. Res., 87, 2108-2108, 1982.

Chen, S.-H., Boardsen, S. A., Fung, S. F. Green, J. L., Kessel, R. L., Chan, L. C., Eastman, T. E., and Craven, J. D.: Exterior and interior cusps: observations from Hawkeye, J. Geophys. Res., 102, $11335-11347,1997$.

Cornilleau-Wehrlin, N., Chanteur, G., Perraut, S., et al.: First Results of the Spatio-Temporal Analysis of Field Fluctuations experiment (STAFF) of Cluster, EGS, 2001.

Cowley, S. W. H.: The causes of convection in the Earth's magnetosphere: A review of developments during the IMS, Rev. Geophys., 20, 531-565, 1982.

Crooker, N. U.: Dayside merging and cusp geometry, J. Geophys. Res., 84, 951-959, 1979.

Dungey, J. W.: Interplanetary magnetic field and the auroral zones, Phys. Rev. Lett., 6, 47-48, 1961.

Dungey, J. W.: The structure of the ionosphere, or adventures in velocity space, in: Geophysics: the Earth's Environment, (Eds) DeWitt, C., Hiéblot, J., and Lebeau, A., 526-536, Gordon and Breach, New York, 1963.

Escoubet, C. P. and Bosqued, J. M.: The influence of IMF- $B_{Z}$ and/or AE on the polar cusp: an overview of observations from the Aureol-3 satellite, Planet. Space Sci., 37, 609-626, 1989.

Escoubet, C. P., Smith, M. F., Fung, S. F., Anderson, P. C., Hoffman, R. A., Basinska, E. M., and Bosqued, J. M.: Staircase ion signature in the polar cusp: a case study, Geophys. Res. Lett., 19, 1735-1738, 1992.

Escoubet, C. P., Bosqued, J. M., Hoffman, R. A., Berthelier, A., and Anderson, P. C.: Opposite ion dispersions observed quasisimultaneously in the polar cusp by the DE-2 and Aureol-3 satellites, Geophys. Res. Lett., 24, 2487-2490, 1997a.

Escoubet, C. P., Schmidt, R., and Goldstein, M. L.: Cluster-Science and mission overview, in: The Cluster and Phoenix Missions, (Eds) Escoubet, C. P., Russell, C. T., and Schmidt, R., 11-32, Kluwer Acad. Publishers, Dordrecht, the Netherlands, $1997 \mathrm{~b}$.

Fedorov, A., Dubinin, E., Song, P., Budnick, E., Larson, P., and Sauvaud, J.-A.: Characteristics of the exterior cusp for steady southward interplanetary magnetic field: Interball observations, J. Geophys. Res., 105, 15 945-15 957, 2000.

Fuselier, S. A., Klumpar, D. M., and Shelley, E. G.: Ion reflection and transmission during reconnection at the Earth's subsolar magnetopause, Geophys. Res. Lett., 18, 139-142, 1991.

Fuselier, S. A., Trattner, R. J., and Petrinec, S. M.: Cusp observations of high- and low-latitude reconnection for northward interplanetary magnetic field, J. Geophys. Res., 105, 253-266, 2000.

Gosling, J. T., Thomsen, M. F., Bame, S. J., Elphic, R. C., and Russell, C. T.: Plasma flow reversals at the dayside magnetopause and the origin of asymmetric polar cap convection, J. Geophys. Res., 95, 8073-8084, 1990.

Gosling, J. T., Thomsen, M. F., Bame, S. J., Elphic, R. C., and Russell, C. T.: Observations of reconnection of interplanetary and lobe magnetic field lines at the high-latitude magnetopause, J. Geophys. Res., 96, 14 097-14 106, 1991.

Kessel, R. L., Chen, S.-H., Green, J. L., Fung, S. F., Boardsen, S. A., Tan, L. C., Eastman, T. E., Craven, J. D., and Frank, L. A.:
Evidence of high-latitude reconnection during northward IMF: Hawkeye observations, Geophys. Res. Lett., 23, 586-589, 1996.

Khrabrov, A. V. and Sonnerup, B. Ö.: DeHoffmann-Teller analysis, in: Analysis Methods for Multi- Spacecraft Data, (Eds) Paschmann, G. and Daly, P. W., ISSI Scientific Report SR-001, 221-248, ESA Pub. Div., Noordwijk, the Netherlands, 1998.

Kudela, K., Sibeck, D. G., Slivka, M., Fisher, S., Lutsenko, V. N., and Venkatesan, D.: Energetic electrons and ions in the magnetosheath at low and medium latitudes: Prognoz 10 data, J. Geophys. Res., 97, 14 849-14 857, 1992.

Le, G. and Russell, C. T.: The thickness and structure of high beta magnetopause current layer, Geophys. Res. Lett., 21, 24512454, 1994.

Lockwood, M. and Smith, M. F.: The variation of reconnection rate at the dayside magnetopause and cusp ion precipitation, J. Geophys. Res., 97, 14 841-14 847, 1992.

Lockwood, M. and Smith, M. F.: Low- and mid- altitude cusp particle signatures for general reconnection rate variations, J. Geophys. Res., 99, 8531-8553, 1994.

Luhmann, J. G., Walker, R. J., Russell, C. T., Crooker, N. U., Spreiter, J. R., and Stahara, S. S.: Patterns of potential magnetic field merging sites on the dayside magnetopause, J. Geophys. Res., 89, 1739-1742, 1984.

Lundin, R.: Plasma composition and flow characteristics in the magnetospheric boundary layers connected to the polar cusp, in: The Polar Cusp, (Eds) Holter, J. A. and Egeland, A., 9-32, D. Reidel Norwell, Mass., 1985.

Lundin, R., Woch, J., and Yamauchi, M.: The present understanding of the cusp, in: Proceedings of the Cluster Workshop, Svalbard, Norway, (Ed) Barron, C. I., ESA SP-330, 83-95, ESA Pub. Div., Noordwijk, the Netherlands, 1991.

Maezawa, K.: Magnetospheric convection induced by the positive and negative $Z$ components of the interplanetary magnetic field: Quantitative analysis using polar cap magnetic records, J. Geophys. Res., 81, 2289-2303, 1976.

Menietti, J. D. and Burch, J. L.: Spatial extent of the plasma injection region in the cusp-magnetosheath interface, J. Geophys. Res., 93, 105-113, 1988.

Oieroset, M., Sandholt, P. E., Denig, W. F., and Cowley, S. W. H.: Northward interplanetary magnetic field cusp aurora and high-latitude magnetopause reconnection, J. Geophys. Res., 192, 11349-11362, 1997.

Onsager, T. G. and Fuselier, S. A.: The location of magnetopause reconnection for northward and southward interplanetary magnetic field, in Solar System Plasmas in: Space and Time, (Eds) Burch, J. L. and Waite, J. H., AGU Geophys. Mon. 84, pp. 183197, AGU, Washington, D. C., 1994.

Papamastorakis, I., Paschmann, G., Baumjohann, W., Sonnerup, B.Ö., and Lühr, H.: Orientation, motion, and other properties of flux transfer event structures on 4 September 1984, J. Geophys. Res., 94, 8852-8866, 1989.

Paschmann, G., Haerendel, G., Sckopke, N., Rosenbauer, H., and Hedgecock, P. C.: Plasma and magnetic field characteristics of the distant polar cusp near local noon: the entry layer, J. Geophys. Res., 81, 2883-2899, 1976.

Paschmann, G., Sonnerup, B.Ö., Papamastorakis, I., Sckopke, N., Haerendel, G., Bame, S. J., Asbridge, J. R., Gosling, J. T., Russell, C. T., and Elphic, R. C.: Plasma acceleration at the Earth's magnetopause: Evidence for magnetic field reconnection, Nature, 282, 243, 1979.

Petrinec, S. M. and Russell, C. T.: Near-Earth magnetotail shape ans size as determined from the magnetopause flaring angle, J. 
Geophys. Res., 101, 137-152, 1996.

Phan, T.-D. and Paschmann, G.: Low-latitude dayside magnetopause and boundary layer for high magnetic shear: 1 . Structure and motion, J. Geophys. Res., 101, 7801-7815, 1996.

Phan, T.-D., Paschmann, G., and Sonnerup, B.Ö.: Low latitude dayside magnetopause and boundary layer for high magnetic shear: 2, Occurrence of magnetic reconnection, J. Geophys. Res., 101, 7817-7828, 1996.

Phan, T.-D., Sonnerup, B. Ö., and Lin, R. P.: Fluid and kinetic signatures of reconnection at the dawn tail magnetopause: Wind observations, J. Geophys. Res., 106, in press, 2001.

Pitout, F., Bosqued, J. M., Alcaydé, D., Denig, W. F., and Rème, H.: Observations of the cusp region under northward IMF, Ann. Geophysicae, this issue, 2001.

Reiff, P. H.: Evidence of magnetic merging from low-altitude spacecraft and ground-based experiments, in: Magnetic Reconnection in Space and Laboratory Plasmas, (Ed) Hones, E. W., AGU Geophys. Mon. 30, 103-113, AGU, Washington, D. C., 1984.

Reiff, P. H., Hill, T. W., and Burch, J. L.: Solar wind plasma injection at the dayside magnetospheric cusp, J. Geophys. Res., 82, 479-491, 1977.

Reiff, P. H., Burch, J. L., and Spiro, R. W.: Cusp proton signatures and the interplanetary magnetic field, J. Geophys. Res., 85, 5997-6005, 1980.

Rème, H., Aoustin, C., Bosqued, J. M., Dandouras, I., et al.: First multispacecraft ion measurements in and near the Earth's magnetosphere with the identical Cluster ion spectrometry (CIS) experiment, Ann. Geophysicae, this issue, 2001.

Rosenbauer, H., Grünwaldt, H., Montgomery, M. D., Paschmann, G., and Sckopke, N.: Heos 2 plasma observations in the distant polar magnetosphere: the plasma mantle, J. Geophys. Res., 80, 2723-2737, 1975.

Russell, C. T.: The structure of the magnetopause, in: Physics of the Magnetopause, (Eds) Song, P., Sonnerup, B. Ö., and Thomsen, M. F., AGU Geophys. Monograph 90, 81-98, AGU, Washington, D. C., 1995.

Russell, C. T., and Elphic, R. C.: Initial ISEE magnetometer results: magnetopause observations, Space Sci. Rev., 22, 681-715, 1978.

Russell, C. T. and Elphic, R. C.: ISEE observations of flux transfer events at the dayside magnetopause, Geophys. Res. Lett., 6, 33-
36, 1979.

Saunders, M. A., Russell, C. T., and Sckopke, N.: Flux transfer events: scale size and interior structure, Geophys. Res. Lett., 11, 2, 131-134, 1984.

Schwartz, S. J.: Shock and Discontinuity Normals, Mach Numbers, and Related Parameters, in: Analysis Methods for MultiSpacecraft Data, (Eds) Paschmann, G. and Daly, P. W., ISSI Scientific Report SR-001, 249-270, ESA Pub. Division, Noordwijk, the Netherlands, 1998.

Scurry, L., Russell, C. T., and Gosling, J. T.: A statistical study of accelerated flow events at the dayside magnetopause, J. Geophys. Res., 99, 14 815-14 830, 1994.

Song, P.: Micro/mesoscale phenomena in the dayside magnetopause: A tutorial, in: Cross-Scale Coupling in Space Plasmas, (Eds) Horwitz, J. L., Singh, N., and Burch, J. L., AGU Geophys. Monograph 93, 235-248, AGU, Washington, D. C., 1995.

Sonnerup, B. U. Ö., Paschmann, G., Papamastorakis, I., Sckopke, N., Haerendel, G., Bame, S. J., Asbridge, J. R., Gosling, J. T., and Russell, C. T.: Evidence for magnetic field reconnection at the Earth's magnetopause, J. Geophys. Res., 86, 10 049-10067, 1981.

Sonnerup, B. U. Ö., Papamastorakis, I., Paschmann, G., and Lühr, H.: Magnetopause properties from AMPTE/IRM observations of the convection electric field: method development, J. Geophys. Res., 92, 12 137-12 159, 1987.

Sonnerup, B. U. Ö., Papamastorakis, I., Paschmann, G., and Lür, H.: The magnetopause for large magnetic shear: Analysis of convection electric fields from AMPTE/IRM, J. Geophys. Res., 95, 10 541-10 557, 1990.

Sonnerup, B. U. Ö., Paschmann, G., and Phan, T.-D.: Fluid aspects of reconnection at the magnetopause, in: Physics of the Magnetopause, (Eds) Song, P., Sonnerup, B. U Ö., and Thomsen, M. F., AGU Geophys. Monogr. 90, 167-180, AGU, Washington, D. C., 1995.

Walthour, D. W. and Sonnerup, B. Ö.: Remote sensing of 2D magnetopause structures, in: Physics of the Magnetopause, (Eds) Song, P., Sonnerup, B. Ö., and Thomsen, M. F., AGU Geophys. Monogr. 90, 247-255, AGU, Washington, D. C., 1995.

Woch, J. and Lundin, R.: Magnetosheath plasma precipitation in the polar cusp and its control by the IMF, J. Geophys. Res., 97, 1431-1447, 1992. 